\title{
Simulation of Winds As Seen By a Rotating Vertical Axis Wind Turbine Blade
}

\author{
R. L. George
}

February 1984

Prepared for the U.S. Department of Energy under Contract DE-AC06-76RLO 1830

Pacific Northwest Laboratory Operated for the U.S. Department of Energy by Battelle Memorial Institute 


\title{
DISCLAIMER
}

This report was prepared as an account of work sponsored by an agency of the United States Government. Neither the United States Government nor any agency thereof, nor any of their employees, makes any warranty, express or implied, or assumes any legal liability or responsibility for the accuracy, completeness, or usefulness of any information, apparatus, product, or process disclosed, or represents that its use would not infringe privately owned rights. Reference herein to any specific commercial product, process, or service by trade name, trademark, manufacturer, or otherwise, does not necessarily constitute or imply its endorsement, recommendation, or favoring by the United States Government or any agency thereof. The views and opinions of authors expressed herein do not necessarily state or reflect those of the United States Government or any agency thereof.

\author{
PACIFIC NORTHWEST LABORATORY \\ operated by \\ BATTELLE \\ for the \\ UNITED STATES DEPARTMENT OF ENERGY \\ under Contract DE-AC06-76RLO 1830
}

\begin{tabular}{|c|c|}
\hline \multirow{2}{*}{\multicolumn{2}{|c|}{ Printed in the United States of America }} \\
\hline & \\
\hline \multicolumn{2}{|c|}{$\begin{array}{c}\text { Available from } \\
\text { Nationat }\end{array}$} \\
\hline \multirow{2}{*}{\multicolumn{2}{|c|}{$\begin{array}{c}\text { National Technical Information Service } \\
\text { United States Department of Commerce } \\
5285 \text { Port Royal Road } \\
\text { Springfield, Virginia } 22161\end{array}$}} \\
\hline & \\
\hline \multirow{2}{*}{\multicolumn{2}{|c|}{$\begin{array}{l}\text { NTIS Price Codes } \\
\text { Microfiche A01 }\end{array}$}} \\
\hline & \\
\hline \multicolumn{2}{|c|}{ Printed Copy } \\
\hline & Price \\
\hline Pages & Codes \\
\hline $001-025$ & $\mathrm{~A} 02$ \\
\hline $026-050$ & $\mathrm{~A} 03$ \\
\hline $051-075$ & $\mathrm{~A} 04$ \\
\hline $076-100$ & A05 \\
\hline $101-125$ & A06 \\
\hline $126-150$ & $\mathrm{~A} 07$ \\
\hline $151-175$ & A08 \\
\hline $176-200$ & $A 09$ \\
\hline $201-225$ & A010 \\
\hline $226-250$ & A011 \\
\hline $251-275$ & A012 \\
\hline $276-300$ & A013 \\
\hline
\end{tabular}


SIMULATION OF WINDS AS SEEN BY A ROTATING VERTICAL AXIS WIND TURBINE BLADE

R. L. George

February 1984

Prepared for the U.S. Department of Energy under Contract DE-AC06-76RLO 1830

Pacific Northwest Laboratory Richland, Washington 99352 


\section{ACKNOWLEDGEMENTS}

The author would like to acknowledge Dr. James Connell, who originated this idea and provided a thorough review of the manuscript. Dr. Robert Akins also provided a timely review and suggested some improvements. Thanks go to Jan Reeder for editorial assistance and help with the figures, and Debbie Atkin for typing the text and tables.

This paper was prepared under U.S. Department of Energy Contract DE-AC06-76RL0-1830. The Pacific Northwest Laboratory is operated for the U.S. Department of Energy by Battelle Memorial Institute. 
, 


\section{SUMMARY}

The objective of this report is to provide turbulent wind analyses relevant to the design and testing of Vertical Axis Wind Turbines (VAWT).

A technique was developed for utilizing high-speed turbulence wind data from a line of seven anemometers at a single level to simulate the wind seen by a rotating VAWT blade. Twelve data cases, representing a range of wind speeds and stability classes, were selected from the large volume of data available from the Clayton, New Mexico, Vertical Plane Array (VPA) project. Simulations were run of the rotationally sampled wind speed relative to the earth, as well as the tangential and radial wind speeds, which are relative to the rotating wind turbine blade. Spectral analys is is used to compare and assess wind simulations from the different wind regimes, as well as from alternate wind measurement techniques. The variance in the wind speed at frequencies at or above the blade rotation rate is computed for all cases, and is used to quantitatively compare the VAWT simulations with Horizontal Axis Wind Turbine (HAWT) simulations. Qualitative comparisons are also made with direct wind measurements from a VAWT blade.

Major conclusions from this study are as follows:

- The characteristic rotationally sampled spectrum, containing spikes at all harmonics of the blade rotation frequency, occurs for VAWT as well as HAWT simulations.

- The rotationally sampled wind speed variance due to turbulence is a roughly linear function of wind speed for neutral and unstable wind conditions. For nighttime stable wind conditions, this relationship is probably nonlinear.

- For tangential and radial winds, the cyclic wind component, due to the upwind and downwind motion of the (simulated) VAWT blade, creates variance in the wind speed spectrum about 100 times greater than the variance due to turbulence in the wind. All of this variance occurs near the blade rotation frequency. 
- Spectra of winds measured directly from a VAWT blade show more energy at higher harmonics of the blade rotation frequency than our wind turbulence simulations. This is presumed to be due to blade wake and aerodynamic effects, which are not being simulated in this study. 


\section{CONTENTS}

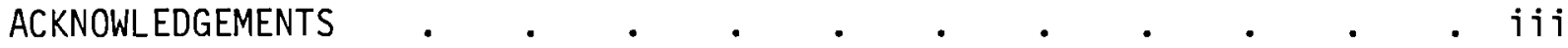

SUMMARY

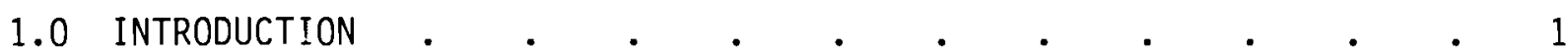

2.0 CLAÝTON VERTICAL PLANE ARRAY-DESCRIPTION AND DATA ANALYSIS . . 3

2.1 VERTICAL PLANE ARRAY: PHYSICAL DESCRIPTION.$\quad$ • . . . 3

2.2 WIND SENSORS AND DATA ACQUISITION $. \quad . \quad . \quad . \quad . \quad . \quad 5$

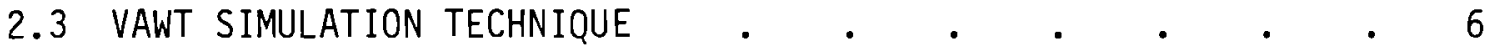

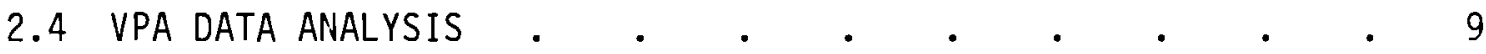

3.0 VAWT SIMULATION DATA ANALYSIS .

3.1 CHARACTERIZATION OF WIND DATA CASES $\quad$ • $\quad$ • $\quad$ • 17

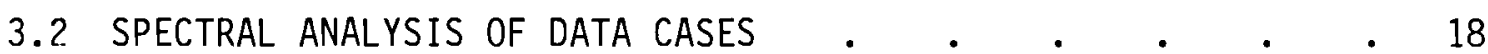

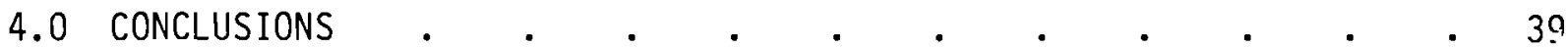

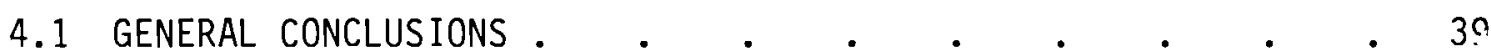

4.2 COMPARISON OF RESULTS WITH DIRECT MEASUREMENTS $\quad \cdot \quad \cdot \quad \cdot 40$

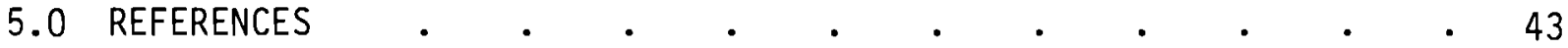


2-1 Clayton Vertical Plane Array . . . . . . . . 4

2-2 (a) Diagram of VAWT Simulation Using a Line of Anemometers

(b) Vector Diagram of Input Winds $v_{r}, U_{i}$, and $v_{i}$ with resultant winds $W_{s}, U_{b}$, and $V_{b}$, as would be seen for the imaginary blade at position 3 .

2-3 (a) Example of $W_{s}$ 1-Blade Time Series for Six Revolutions of the Imaginary Blade, (b) Example of $W_{s} 2$-Blade Time Series, for Same Time as (a), (c) Example of $U_{b}$ 1-Blade Time Series, Same Time as (a), (d) Example of $U_{b}$ 2-Blade Time Series, Same Time as (a)

2-4 The Actual Wind Speed Observed at Single Anemometer Locations for the Same Time Period as Figure 2-3 . . . . . . . 12

2-5 Spectral Density Plots, Al1 for the Same 8.53 Minute Period (Case Cla), (a) Eulerian, or Fixed Point Wind Speed, (b) VAWT 1 Blade Simulation, Wind Speed, (c) VAWT 2 Blade Simulation, Wind Speed (d) $U_{b}$, the Wind Tangential to the Blade, for 1 Blade

3-1 Complete Set of Spectral. Plots for Case Cla, (a) $W_{S}, 1$ Blade (same as 4-5b), (b) $W_{s}, 2$ Blade (same as 4-5c), (c) $U_{b} 1$ Blade (same as 4-5d), (d) $U_{b}, 2$ Blade, (e) $V_{b}$, the Radial Wind Component, for 1 Blade, ( $f$ ) $V_{b}, 2$ Blade, (g) Wind Speed for the Horizontal Axis Wind Turbine Simulation, 1 Blade,

(h) Eulerian or Fixed-Point Wind Speed (same as 4-5a) . . . 19

3-2 Spectral Plots of Case Cla, for a Simulated 20 RPM VAWT, (a) $w_{s} 1$ Blade, Original Data, (b) $w_{s}, 1$ Blade Anemometer Data Filtered With a 15 Point (3.75 Second) Lowpass Filter Before Rotational Sampling, (c) $U_{b}, 1$ Blade, (d) $U_{b}, 1$ Blade 3.75-Sec Filter, (c) $V_{b}, 1$ Blade, (f) $V_{b}, 1$ Blade, 3.75-Sec Filter • . 20

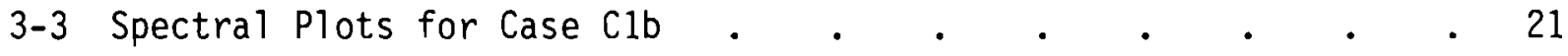




\section{FIGURES (Continued)}

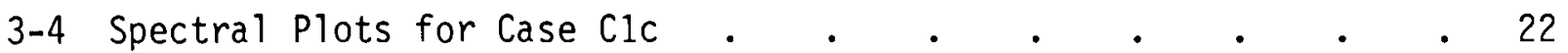

3-5 Spectral Plots for Case C2a . . . . . . . . . . . 23

3-6 Spectral Plots for Case C2b . . . . . . . . . . . 24

3-7 Spectral Plots for Case C2c .

3-8 Spectral Plots for Case C3a

3-9 Spectral Plots for Case C3b $\quad$ •

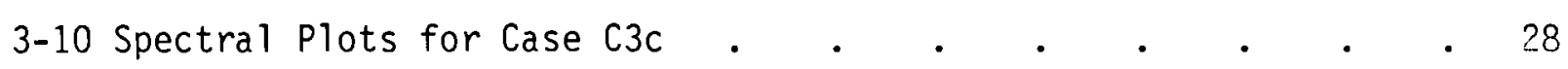

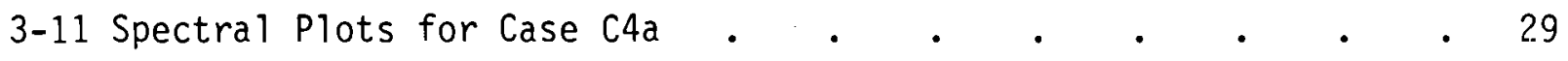

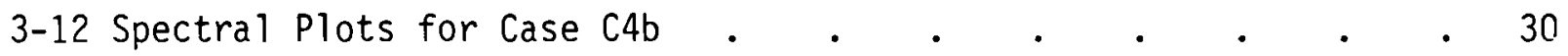

3-13 Spectral Plots for Case C4c . . . . . . . . . . . . 31

3-14 Plot of Total Variance in A11 5 Turbulent Spikes Vs. Wind Speed

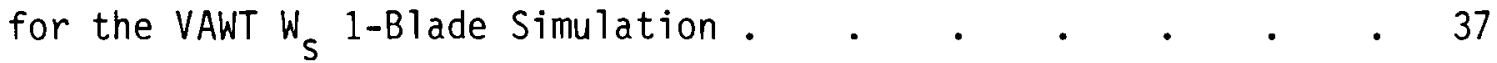

3-15 Plot of Variance, $\sigma_{i}{ }^{2}$, in Each Individual Spike, Vs. Frequency, for A11 12 Data Cases . . . . . . . . . . . . 38

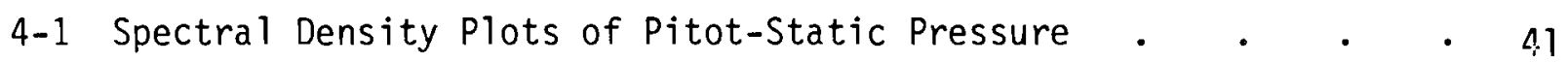

\section{$\underline{\text { TABLES }}$}

3-1 Summary of Characteristics of 12 Data Cases Used in VAWT

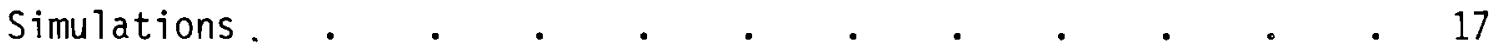

3-2 Variance in Each Spike, Cases C1 and C2 . . . . . . . 34

3-3 Variance in Each Spike, Cases C3 and C4 . . . . . . . 35

3-4 Linear Curve Fit Coefficients to Spike Profiles for 12 Data

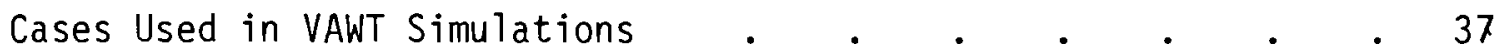




\subsection{INTRODUCTION}

The influence of the turbulent wind on a moving wind turbine blade has recently emerged as a significant consideration for wind turbine design. The stresses on the rotating blade caused by instantaneous wind shears encountered by the blade within each revolution have been found to be more severe and more difficult to understand than previously expected. Since 1977, the Pacific Northwest Laboratory (PNL) has been conducting a program of measuring the wind as seen by a rotating Horizontal Axis Wind turbine (HAWT) blade, using fixed arrays of towers and anemometers (Verholek 1978, Connel1 1981). In the most elaborate of these studies, an array of towers and anemometers was placed two biade diameters upwind of a large HAWT, which was the MOD-OA at Clayton, New Mexico (Connel1 and George 1982, 1983a). Good correlation was observed between the spectrum of the rotationally sampled wind and the stresses on the rotating MOD-OA blade. As part of the Clayton data set, a large amount of data was obtained from a line of seven anemometers, all at the same level (30.5 $\mathrm{m}$ above ground level). A major purpose in setting up the seven anemometers was to provide a data set which can be used to simulate the winds seen by a rotating Vertical Axis Wind Turbine (VAWT) blade.

The purpose of this study is to estimate and characterize the turbulence effects on a rotating VAWT blade using data from the seven anemometers. The expected wind as seen by the rotating VAWT blade, due only to the free stream mean wind and turbulent wind fluctuations, will be synthesized. This simulation will not attempt to show the effects of blade wakes, wind turbine structure wakes, or blade stall on the wind turbine blade. Spectral analysis techniques will be used to characterize the turbulence observed by the imaginary VAWT blade, with the emphasis on frequencies equal to or higher than the blade rotation frequency. Since no VAWT existed at the site, no attempt can be made to compare wind turbine stress directly with the rotationally sampled wind. However, our results will be compared with wind measurements obtained from a moving VAWT blade.

The organization of this report is as follows. Chapter 2 starts with a physical description of the Clayton Vertical Plane Array (VPA) and the 
anemometers used there to measure the wind. Then a description of the technique of VAWT simulation follows, using a sequence of wind speeds appropriately led and lagged in time to simulate the motion of the wind turbine blade. Examples of the time series of rotational and fixed-point wind speed are given as aids in understanding the process. Then, a description of the use of spectral density is given, along with features of the fixed-point, one-blade simulation, and two-blade simulation spectral plots. These plots are characterized by spikes in the spectra, occurring at multiples of the wind turbine rotation frequency. A method is then presented to estimate the variance in the wind speed contained in each spike.

In Chapter 3, 12 data cases, belonging to four distinct wind regimes at Clayton, are selected for spectral analysis. Comparison is made of the rotationally sampled spectra and the fixed point, or Eulerian spectra, among the four categories of wind. The variances due to each spike are tabulated for all the cases. Relationships between the spike variance and wind speed are discussed, along with the relative sizes of the spikes. In the last chapter, we express conclusions about the Clayton VAWT analysis. We then compare our results with another VAWT study, a wind measurement from a rotating VAWT blade (Akins 1983). 


\subsection{VERTICAL PLANE ARRAY: DESCRIPTION AND DATA ANALYSIS}

A Vertical Plane Array (VPA) of anemometers was operated by PNL between May 1981 and August 1982 at Clayton, New Mexico. The VPA was operated in conjunction with the MOD-OA1, a $200 \mathrm{~kW}$ wind turbine operated by the National Aeronautics and Space Administration (NASA) for the U.S. Department of Energy (DOE). In this chapter, we will describe the physical configuration of the VPA and the wind sensors used to take the wind data. We will also describe the data taking procedures used at Clayton, and the process of selecting data cases. Finally, we will discuss the analysis of the wind data using rotational sampling techniques and spectral analysis.

\subsection{VERTICAL PLANE ARRAY: PHYSICAL DESCRIPTION}

The VPA consisted of seven triangular guyed steel towers, each $60.6 \mathrm{~m}$ (199 feet) tall (Figure 2-1). The towers were located in a straight 1 ine which was placed at right angles to a line from the center tower to the MOD-OA1 turbine. The towers were unevenly spaced in order to accommodate a ring of 12 anemometers, which were evenly spaced around a circle $38.1 \mathrm{~m}$ (125 feet) in diameter. The center of the circle was elevated $30.5 \mathrm{~m}$ (100 feet) above ground leve1. These dimensions correspond to the height and diameter of the MOD-OA rotor for standard rotor blades. Additional anemometers were located at $60.0 \mathrm{~m}$ (197 feet) on the center tower and at $30.5 \mathrm{~m}$ (100 feet) on the five interior towers. Data from these extra anemometers will be used in this paper to simulate the wind seen by a Vertical Axis Wind Turbine (VAWT) blade. Thus, for the present analysis, we are concerned only with the seven anemometers, one on each tower of the VPA, which were at the $30.5-\mathrm{m} \mathrm{level}$.

The Clayton, New Mexico, MOD-OA site was chosen over the five other NASA wind turbine sites because of the flatness and uniformity of the terrain. The most frequent wind direction at Clayton is SSW or SW. The VPA was located and the anemometers exposed so as to give the best wind data in this direction. South to southwest of the VPA is also the flattest, most uniform terrain at this site. Analysis of VPA data has indicated a roughness length (used in logarithmic wind law calculations) of about $0.005 \mathrm{~m}$, a length usually 


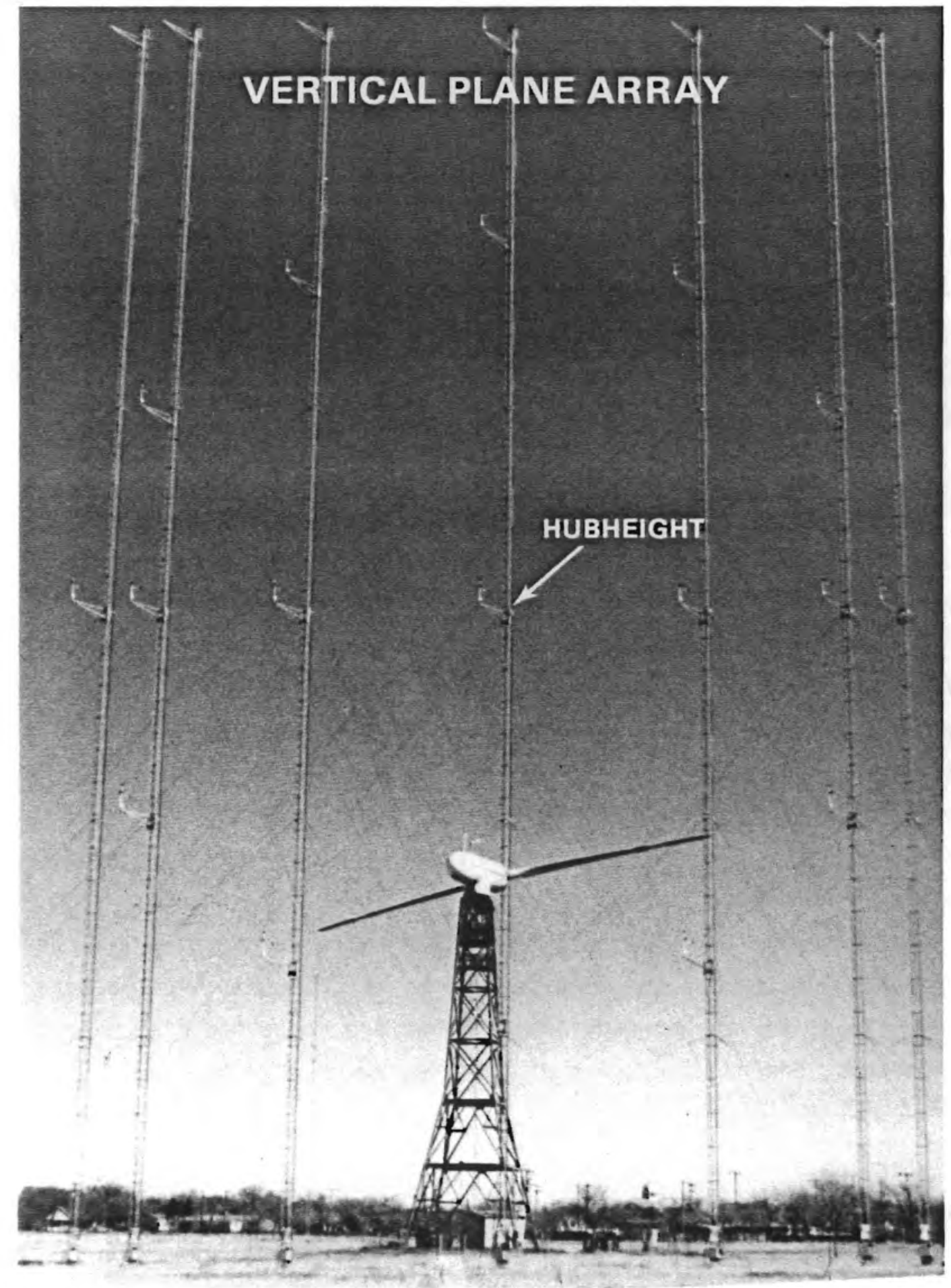

FIGURE 2-1. Clayton Vertical Plane Array. The seven anemometers at the level marked "Hub Height" were used for the VAWT simulations. 
associated with mown grass (Chan et al. 1983). The terrain to the west of the site is much rougher, with a rocky ravine about $100 \mathrm{~m}$ away.

\subsection{WIND SENSORS AND DATA ACQUISITION}

The wind sensors used on all the VPA towers are R. M. Young Model 27004 Gill UVW anemometers. Each anemometer consists of three small propeller anemometers mounted at orthogonal right angles to each other. All anemometers were mounted such that the primary component, known as the $U$ direction, faced into the normal array wind direction of $205^{\circ}$. The cross-wind component is known as $V$ and the vertical wind component as $W$. Thus, for a uniform wind direction of $205^{\circ}, \mathrm{U}$ is the wind speed and $\mathrm{V}$ is close to zero. The analysis in this report will utilize both the $U$ and $V$ components.

The propellers mounted on the Gill UVWs were rugged black polypropylene propellers $18 \mathrm{~cm}$ in diameter (referred to by R. M. Young as 'High Resolution Propeller'). The distance constant, a measure of the responsiveness of the propeller to rapid changes in the wind speed, is $3.3 \mathrm{~m}$ for these propellers. For rapid wind speed changes, the propeller acts as a first-order filter with a time constant equal to distance constant divided by mean wind speed (Horst 1973). Wind data from UVW anemometers require correction to account for the fact that the propeliers do not respond fully to winds at high angles to the axis of the component. The raw data must be corrected to more accurately represent the wind speed. This correction was performed on all data which are presented in this report. However, the impact of correction on the measured axial wind speeds is very small. The corrections were performed with revised correction coefficients for use with the 18-cm polypropylene propeller.

The VPA was operated from May 1981 to July 1982. Several hundred hours of high speed VPA data, along with MOD-OA wind turbine parameters, were taken during this period. In addition, over 1 year's worth of climatological data from only the center tower are available. The 12 cases of high-speed VPA data used in this paper were chosen originally for a project to compare VPA data with MOD-OA blade bending moments. They have been chosen to represent different wind conditions, when the MOD-OA with blade bending signals was operating 
properly. For other purposes, the amount of available data is much larger. Doran and Packard (1982) have selected data from eight different days for use in the study of wind turbine wakes. Since the MOD-OA power signal was always available, most of the data are usable for wind turbine performance evaluation, in a much more detailed manner than ever before. Miller and Formica (1983) have used the climatological data as input to a model of the MOD-OA control strategy. Chan et al. (1983) have also used the climatological data to address the problem of wind turbine array modeling. A set of full array and wind turbine data have also been provided to NASA-Lewis Research Center, designers of the MOD-OA, for use in their blade pitch optimization project.

\subsection{VAWT SIMULATION TECHNIQUE}

Given an imaginary VAWT with blade radius $R$, measured from the axis to the equator. The blade rotates at a frequency

$$
n_{0}=2 \pi \omega
$$

Thus, the blade element on the equator moves at a rotational speed

$$
V_{r}=R \omega=R n_{0} /(2 \pi)
$$

Along this equator are 12 equally spaced imaginary anemometer locations, labeled $i=1,12$ (Figure 2-2a). The blade is assumed to start at the leftmost position, facing northeast, and to move counter-clockwise. The blade element experiences a wind due to its motion which is equal to $v_{r}$ and opposite in direction. The angle between the starting position and the present position $i$ is thus

$$
\phi i=(i-1)(360 / 12)^{\circ}
$$

The blade moves to a new location every $1 /\left(12 n_{0}\right)$ seconds. A real anemometer $j(i)$ is associated with each imaginary location $i$, as shown on Figure $2-2 a$. We have recorded the wind speed time series $U_{0}(j, t)$ and $v_{0}(j, t)$, the along-wind 
$011 \quad 09$

$012 \quad 08$

(a)

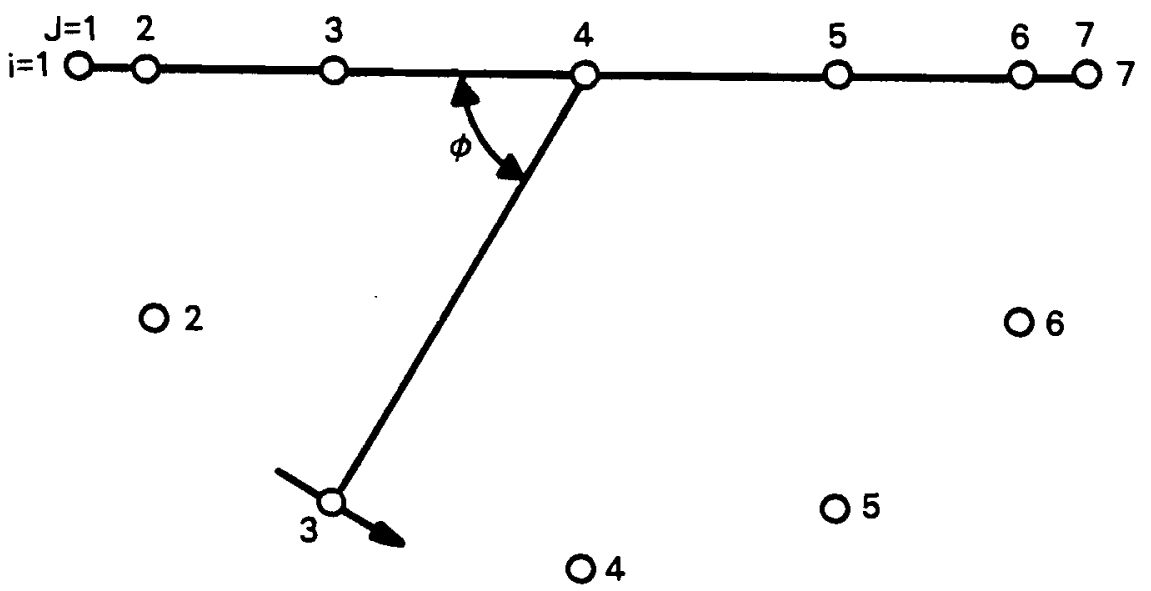

(b)

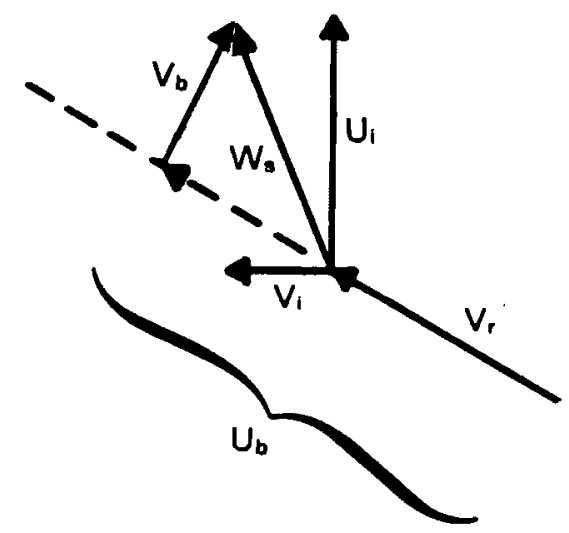

FIGURE 2-2. (a) Diagram of VAWT Simulation Using a Line of Anemometers. Blade is rotating CCW, looking down from above. (b) Vector diagram of input winds $V_{r}, U_{i}$, and $V_{i}$, with resultant winds $w_{s}$, $U_{b}$, and $V_{b}$, as would be seen for the imaginary blade at position 3 , as shown in (a). $V_{r}$ is an induced wind in the opposite direction to blade motion. 
and cross-wind components, at intervals of $\Delta t=0.25$ seconds. We use 1 inear interpolation in time on each of these time series to get $U_{0}(j, t)$ and $V_{0}(j, t)$ for any desired time. If $t_{j}$ is the time the blade passes location $i$, we calculate the time for the wind to advect from the anemometer to location $i$ using the equation:

$$
R \operatorname{SIN}_{i}=\int_{t_{i}}^{t_{j}+\Delta t_{a}} U_{0}[j(i), t] d t
$$

and use a finite difference technique to solve for the advection time $\Delta t_{a}$. This assumes that the wind direction is close to the array direction, such that $U_{0}$ is the principal component. This is true for all the cases studied. We then have the components of the observed wind at the time of blade passage of location $i$ :

$$
\begin{aligned}
& U\left(i, t_{j}\right)=U_{0}\left[j(i), t_{i}+\Delta t_{a}\right] \\
& V\left(i, t_{j}\right)=V_{0}\left[j(i), t_{j}+\Delta t_{a}\right]
\end{aligned}
$$

From these we will compute three different time series of rotational wind:

$$
\text { 1. } w_{s}\left(i, t_{i}\right)=\left[U\left(i, t_{i}\right)^{2}+V\left(i, t_{i}\right)^{2}\right]^{1 / 2}
$$

the observed wind speed at time of blade passage;

$$
\text { 2. } U_{b}\left(i, t_{i}\right)=V r+U\left(i, t_{i}\right) \cos \phi_{i}+V\left(i, t_{i}\right) \sin \phi_{i}
$$

the chordwise, or tangential wind observed by the rotating blade; and

$$
\text { 3. } V_{b}\left(i, t_{i}\right)=V\left(i, t_{i}\right) \cos \phi_{i}-U\left(i, t_{i}\right) \sin \phi_{i}
$$


the flapwise, or radial wind observed by the rotating blade. Figure 2-2b $i l l u s t r a t e s$ how the known wind vectors $U_{i}, V_{i}$, and $V_{r}$ are combined to get the desired vectors $W_{s}, U_{b}$, and $V_{b}$. A positive $V_{b}$ indicates a net wind coming from the left side of the blade element as it moves around; that is, from the hub toward the outside.

Provision was made to model a multibladed VAWT by averaging the rotational time series taken simultaneously at the proper locations. Thus, for a twobladed turbine, the wind observed at the opposite location was averaged with the wind from the current blade location. The results of analysis of these time series should be related to the torque and power fluctuations observed at the hub of a VAWT. No attempt was made to model any other aspects of the vertical axis wind turbine, such as the wake effects from the hub or the upwind blade. We are constrained by the geometry of the VPA to use a blade radius

$$
R=19.05 \mathrm{~m}
$$

However, we can simulate any blade rotation rate, $n_{0}$. A rotation rate of $0.6667 \mathrm{~Hz}$, or $40 \mathrm{rpm}$, was used for most of the analyses in this report.

\subsection{VPA DATA ANALYSIS}

Time series from the first VPA data case analyzed in this fashion are shown in Figure 2-3. These data are from November 25, 1981 at about noon standard time, a case which will be referred to in the next chapter as Case Cla. The vertical grid lines are one blade revolution apart, or 1.5 seconds for a $40 \mathrm{rpm}$ rotation rate. Figure $2-3 a$ is the $w_{S}$ for a one-blade simulation. Within this short period of six revolutions of the imaginary blade, the character of this signal changed from principally one cycle of fluctuation per revolution to two-per-revolution and back again to one. Fluctuations with amplitudes of over $1 \mathrm{~m} / \mathrm{sec}$ are apparent. Figure 2-3b is the observed wind speed averaged over two blades. It has a more consistent two-per-revolution character. 


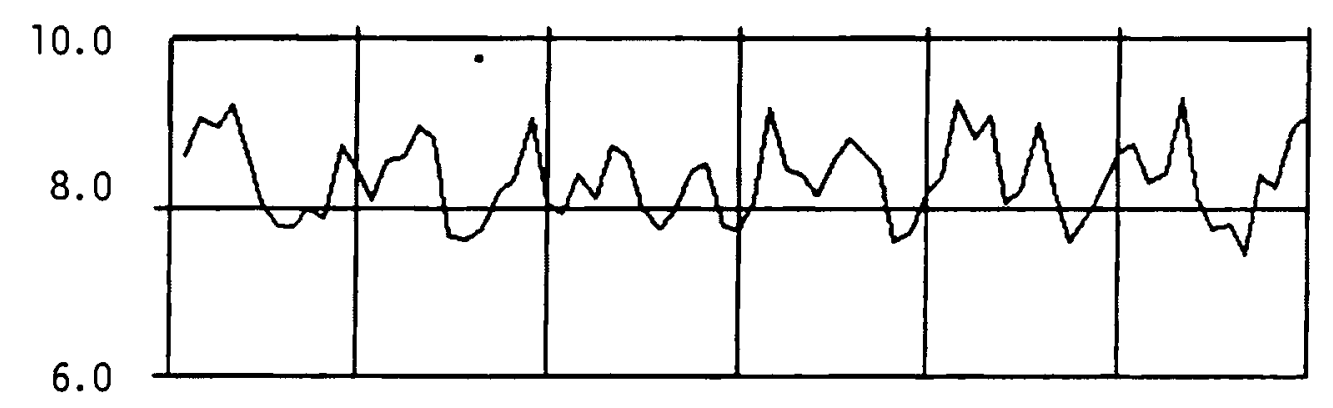

(a)

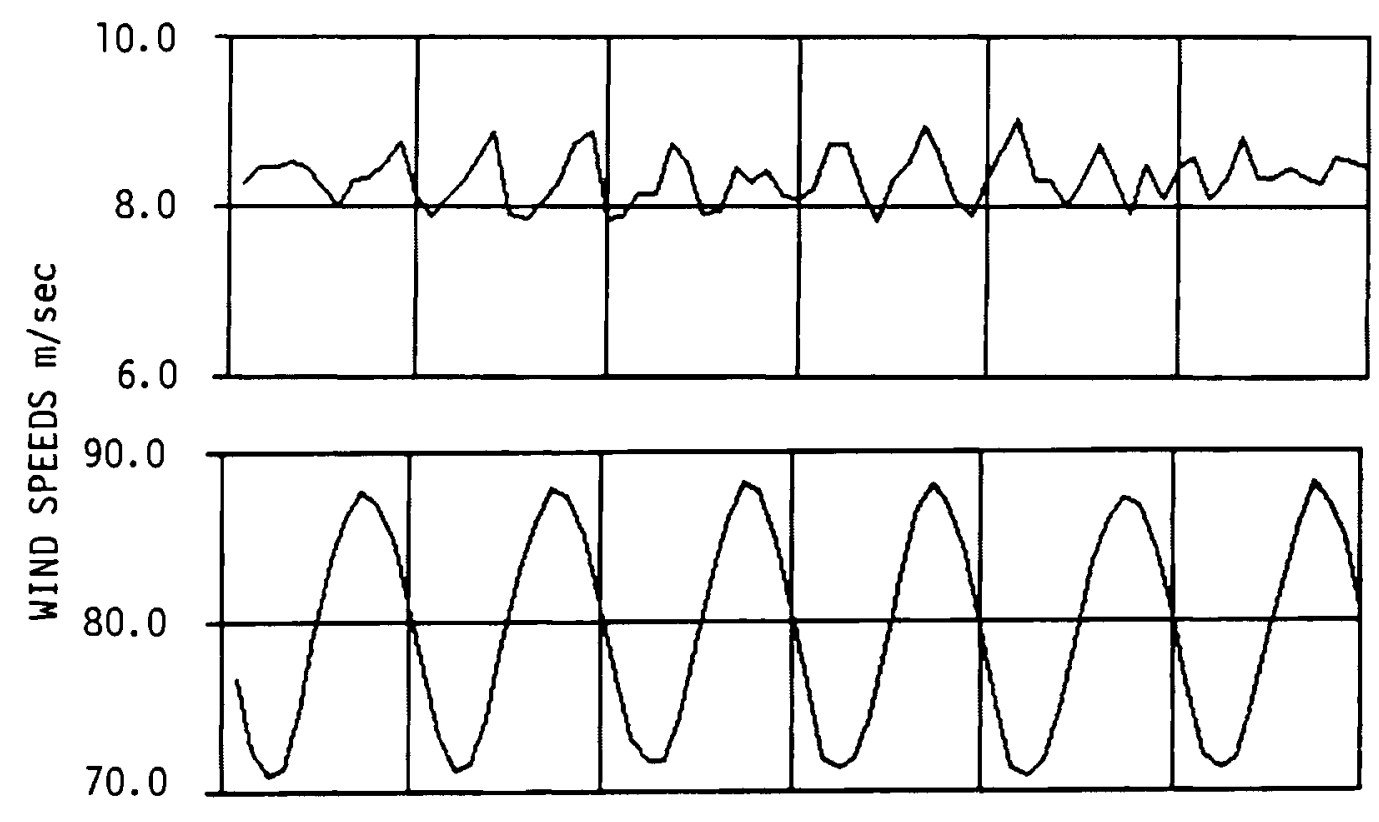

(b)

(c)

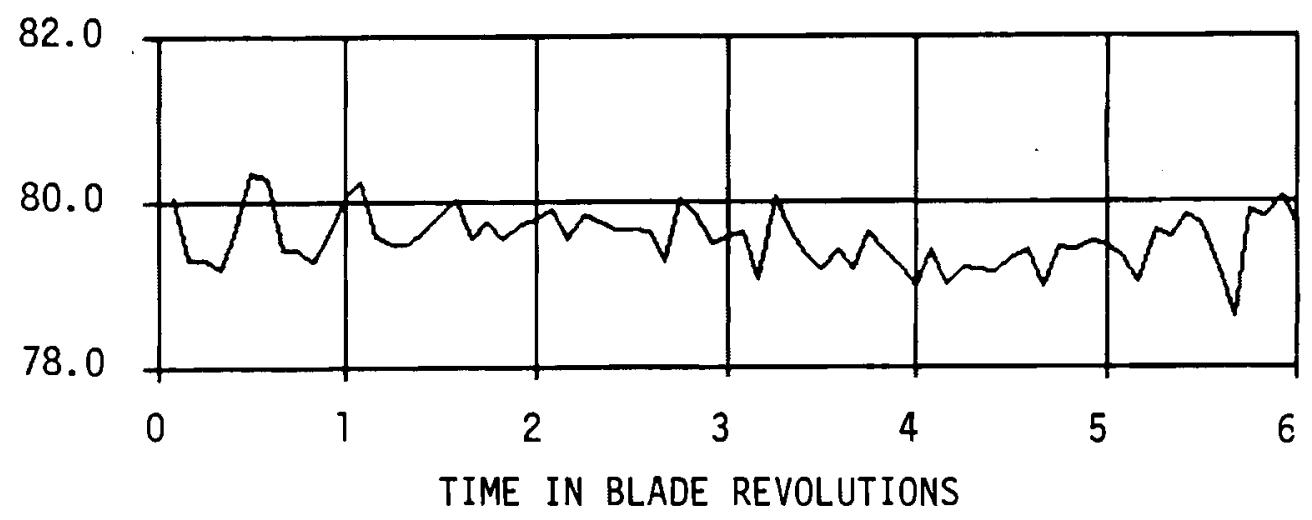

FIGURE 2-3. (a) Example of $W_{S} 1-B l a d e$ Series for Six Revolutions of the Imaginary Blade, (b) Example of $W_{s} 2-B 1$ ade Time Series, for Same Time as (a), (c) Example of U $U_{b} 1-B 1$ ade Time Series, Same Time as (a), (d) Example of $U_{b}$ 2-Blade Time Series, Same Time as (a). 
Figure $2-3 c$ is $U_{b}$, the tangential wind observed by the rotating VAWT blade. It has a large sinusoidal fluctuation with a peak-to-peak amplitude of twice the mean wind speed, or over $16 \mathrm{~m} / \mathrm{sec}$ in this case. Small fluctuations due to the turbulent wind are not noticeable on this plot. The average speed of $U_{b}$ is $79.8 \mathrm{~m} / \mathrm{sec}$, which is $V_{r}$, the blade rotation speed. In Figure 2-3d, the two-blade average of $U_{b}$ is seen to two-per-revolution character.

In Figure 2-4, the $U$ component of the wind observed directly by the Gill anemometers is presented for the same time period as in Figure 2-3, for the leftmost, center, and rightmost array positions. This figure can be compared to Figure 2-3 to demonstrate how localized wind gusts serve to create the characteristic rotationally sampled time series.

Power spectral density (PSD) functions were chosen for data analysis in order to provide a means of comparison between wind data and wind turbine response, in a form familiar to both boundary-layer meteorologists and wind turbine engineers. PSD functions were created using a Fast Fourier Transform (FFT) routine. Variances integrated over the spectral domain are also computed using the FFT routine. The FFT spectral analysis technique requires that the input data stream consist of a number of data points equal to an integral power of 2. The data segments analyzed in this paper are 8.53 minutes long, or 512 seconds. For rotational winds, the data rate is 8 per second (one data point each 0.125 second), each spectrum contains 4096 data.points $\left(2^{12}\right)$, and the highest frequency is $4.0 \mathrm{~Hz}$ (Figure 2-5).

A PSD plot from the VPA for a single anemometer at the center is shown in Figure 2-5a. Atmospheric turbulence, when plotted in this manner, usually exhibits a falloff with increasing frequency which has a slope of $-5 / 3$ on a $\log -\log$ plot, as is indicated with a diagonal dashed line on Figure 2-5. The deviation of our observed response from the theoretical is due to the lack of frequency response of the propeller anemometer. The spectra in Figure 2-5b, $c$ and $d$ contain spikes corresponding to the rotation rate of the wind turbine.

For one blade (2-5b and d) a spike occurs at integer multiples of the rotation frequency, which is $0.666667 \mathrm{~Hz}$, referred to as ' $P$ '. For two-blade spectra (Figure 2-5C), only even multiples of $P(2 P, 4 P$, etc.) are present. 


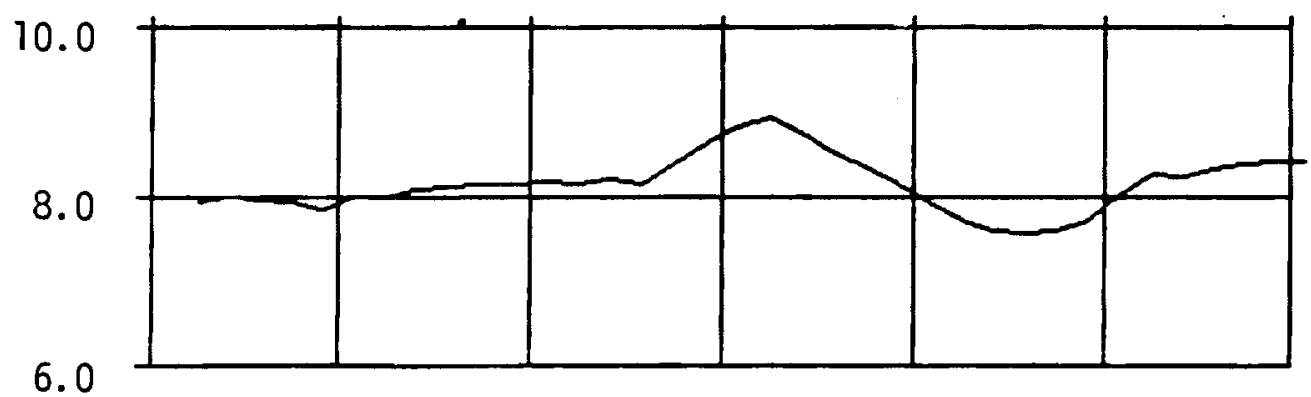

(a)

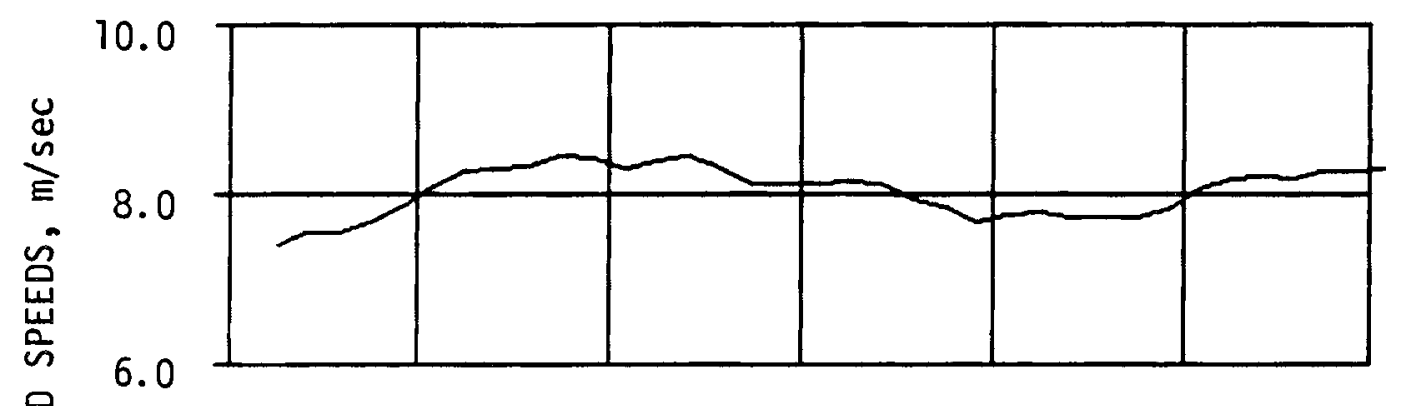

(b)

을

10.0

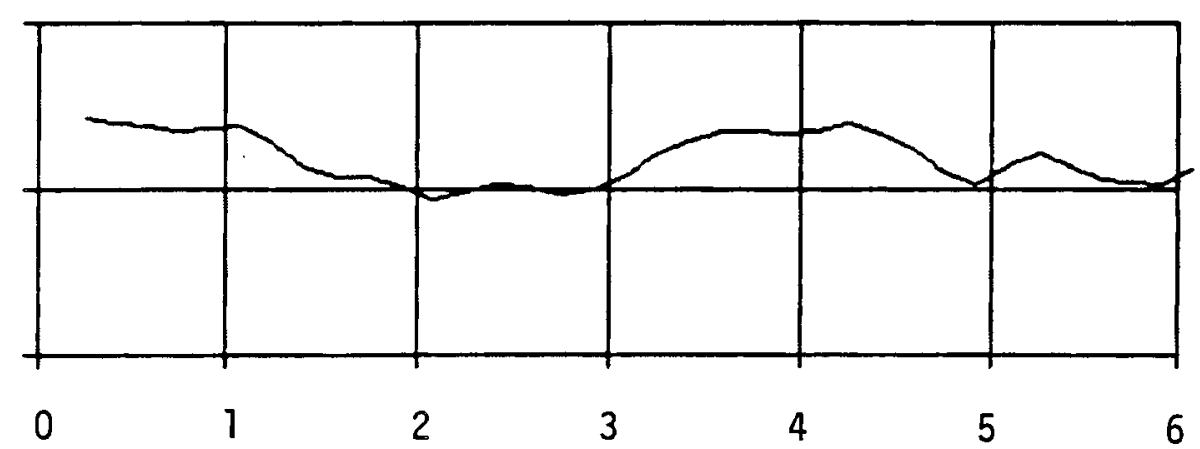

(c)

TIME IN BLADE REVOLUTIONS

FIGURE 2-4. The Actual Wind Speed Observed at Single Anemometer Locations for the Same Time Period as Figure 2-3. (a) Leftmost anemometer, $j=1$; (b) center anemometer, $j=4$; (c) rightmost anemometer, $j=7$. 

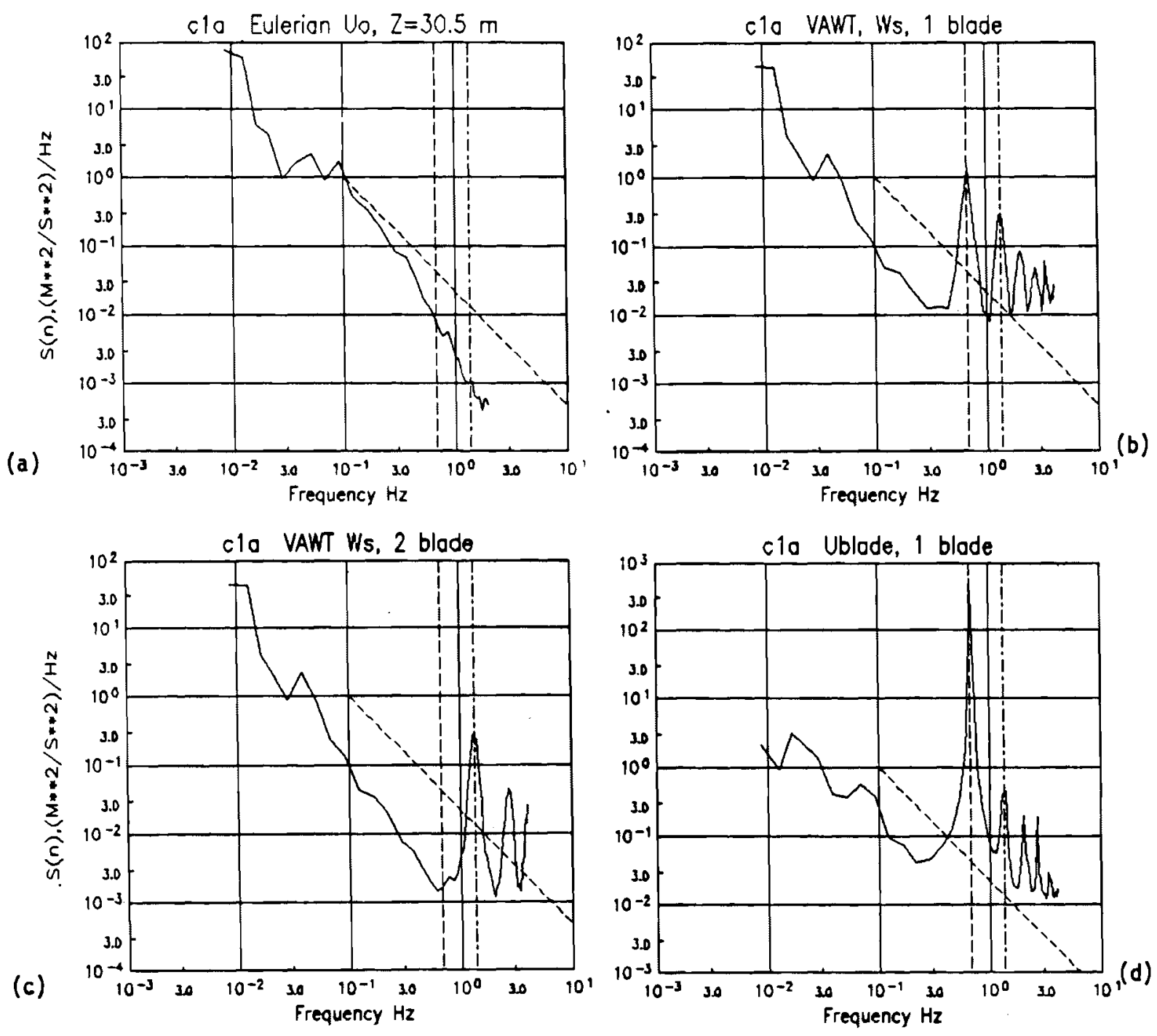

FIGURE 2-5. Spectral Density Plots, A11 for the Same 8.53 Minute Period (Case Cla), (a) Eulerian, or Fixed Point Wind Speed, (b) VAWT 1 Blade Simulation, Wind Speed, (c) VAWT 2 Blade Simulation, wind Speed, (d) $U_{b}$, the Wind Tangential to the Blade, for 1 Blade. The vertical scale of this plot is shifted downward by 10 to accommodate the large spike. The diagonal dashed line is the maximum theoretical spectral density for a fixed-point anemometer. The vertical dashed 1 ines are the $1 P$ and $2 P$ frequencies. 
On this plot and all other wind spectral plots in this report, the $1 P$ and $2 P$ frequencies are marked by vertical dashed 1 ines.

The spectrum of VAWT wind speed in Figure 2-5b is reduced below the spectrum of Eulerian wind in the frequency range $0.05-0.5 \mathrm{~Hz}$. A roughly equal amount of energy is distributed among the five spikes at frequencies above $0.5 \mathrm{~Hz}$. This result is consistent with previously reported Horizontal Axis VPA results (Connel1 and George 1982). The entire structure of this spectrum above $0.5 \mathrm{~Hz}$ is attributable to wind turbulence, since no mean wind shears are present. The spikes in Figure 2-5c, the two-bladed simulation, have the same magnitude as the spikes in 2-5b, for the even-numbered values of $P$ only. Spectral density at odd-numbered values of $P$ is eliminated by twoblade averaging.

The spectrum of $U_{b}$, the tangential velocity of winds as seen by the rotating turbine blade, is fundamentally different from other rotational spectra we have seen. An enormous spike, reflecting the one-per-revolution cycle of $U_{b}$ as seen in Figure 2-3c, dominates the spectrum in Figure 2-5d. However, the spikes at $2 \mathrm{P}$ through $5 \mathrm{P}$ are similar in size to those present on the VAWT wind speed spectrum (Figure 2-5b). At low frequencies, the $U_{b}$ spectrum is greatly reduced compared to the wind speed spectrum. The spectrum of $V_{b}$ is very similar to that of $U_{b}$.

The plots of spectral estimates in this paper are of $S(n)$ versus $n_{0} \cdot S(n)$ has the units of $\left(\mathrm{m}^{2} / \mathrm{sec}^{2}\right) / \mathrm{Hz}$. When the spectral density $S(n)$ is integrated over a range of frequency, an estimate is obtained of the variance in the time series due to fluctuations whose frequencies fall within that range. If $n_{0}$ is the rotational frequency of the (imaginary) VAWT blade, then we define a variance $\sigma_{i}^{2}$ such that

$$
\sigma_{i}^{2}=\int_{(i-0.5) n_{0}}^{(i+0.5) n_{0}} s(n) d n \text { for } i=1,2,3,4,5
$$

is the variance associated with each harmonic of the rotational frequency (each "spike" on the rotationally sampled spectrum), and 


$$
\sigma_{0}^{2}=\int_{0}^{0.5 n_{0}} S(n) d n
$$

is the variance due to low frequency wind fluctuations. These variance values will be calculated and used in the next chapter to compare the rotationally sampled spectra from various wind cases and various simulation types. This technique has previously been used to assess single tower simulations of various sized HAWTs (Connel1 and George 1983b). 



\subsection{VAWT SIMULATION DATA ANALYSIS}

The data analysis techniques presented in the previous chapter were applied to 12. separate data cases from the Clayton VPA data set, each case being 8.53 minutes long. These cases were originally chosen for a Horizontal Axis Wind Turbine (HAWT) study. Thus, simulations of the wind rotationally sampled in the vertical plane are available for all cases, for comparison with the VAWT simulation data.

\subsection{CHARACTERIZATION OF WIND DATA CASES}

The 12 cases are listed in Table 3-1.

TABLE 3-1. Summary of Characteristics of 12

Data Cases Used in VAWT Simulations

\begin{tabular}{|c|c|c|c|c|c|c|c|}
\hline Case \# & Date & $\begin{array}{l}\text { Time } \\
\text { MST } \\
\end{array}$ & $\begin{array}{l}\text { Mean WS } \\
\text { M/Sec }\end{array}$ & $\sigma / W S$ & $\begin{array}{c}\text { Tip } \\
\text { Speed } \\
\text { Ratio } \\
\end{array}$ & $\begin{array}{c}\text { VAWT } \\
\text { Spike } \sigma^{2} \\
M^{2} / S^{2} \\
\end{array}$ & $\begin{array}{c}\text { HAWT } \\
\text { Spike } \sigma^{2} \\
M^{2} / S^{2} \\
\end{array}$ \\
\hline $\mathrm{Cla}$ & $11 / 25 / 81$ & 1211 & 7.66 & 0.089 & 10.4 & 0.286 & 0.411 \\
\hline $\mathrm{C} 1 \mathrm{~b}$ & $06 / 28 / 82$ & 1350 & 6.82 & 0.120 & 11.7 & 0.263 & 0.406 \\
\hline $\mathrm{Clc}$ & $06 / 28 / 82$ & 0818 & 7.68 & 0.089 & 10.4 & 0.322 & 0.521 \\
\hline $\mathrm{C} 2 \mathrm{a}$ & $01 / 01 / 82$ & 1231 & 9.87 & 0.077 & 8.1 & 0.301 & 0.913 \\
\hline $\mathrm{C} 2 \mathrm{~b}$ & $11 / 27 / 81$ & 1455 & 10.56 & 0.101 & 7.6 & 0.435 & 1.046 \\
\hline $\mathrm{C} 2 \mathrm{c}$ & $11 / 27 / 81$ & 1143 & 13.61 & 0.077 & 5.9 & 0.483 & 1.505 \\
\hline C3a & $07 / 01 / 82$ & 0124 & 5.95 & 0.100 & 13.4 & 0.255 & 0.632 \\
\hline$c 3 b$ & $12 / 18 / 81$ & 1608 & 5.90 & 0.052 & 13.5 & 0.082 & 0.827 \\
\hline $\mathrm{C} 3 \mathrm{c}$ & $12 / 14 / 81$ & 1624 & 5.70 & 0.036 & 14.0 & 0.034 & 0.701 \\
\hline C4a & $01 / 01 / 82$ & 1803 & 12.52 & 0.086 & 6.4 & 0.700 & 2.568 \\
\hline c4b & $01 / 01 / 82$ & 1546 & 12.32 & 0.083 & 6.5 & 0.662 & 2.266 \\
\hline $\mathrm{C} 4 \mathrm{c}$ & $01 / 01 / 82$ & 1825 & 14.00 & 0.072 & 5.7 & 0.732 & 3.392 \\
\hline
\end{tabular}

The turbulence intensity, Column 5 in the Table, was computed by taking the standard deviation of the wind speed after removing all fluctuations longer than about 2 minutes, and dividing by mean wind speed. Tip speed ratio 
(Column 6) was obtained using the tip speed of a 19.05-m radius blade rotating at $40 \mathrm{rpm}$, which was $79.8 \mathrm{~m} / \mathrm{sec}$, and dividing by the mean wind speed. The total variance in the $1 P$ through $5 P$ spikes of the wind speed simulation is given for both VAWT (Column 7) and HAWT (Column 8).

Case $\mathrm{C} 1$ consisted of daytime, neutral-to-unstable, low-wind speed cases. These cases at Clayton were characterized by very low vertical wind shears. The turbulence intensities of 0.09 to 0.12 are typical for a flat site. Total variance in the five spikes is $60-70 \%$ of that observed using a full ring of anemometers (see Figure 2-1) to simulate a HAWT.

Case $\mathrm{C} 2$ contains higher wind speed cases of daytime, neutral-to-uristable winds. The turbulence intensity was slightly lower for these cases. Moderate vertical wind shears were present, causing the VAWT variance to be only $32-42 \%$ of the HAWT variance, which contains energy due to mean wind shear.

Cases C3 and C4 were evening and nighttime cases with more stable wind shear profiles. C3a was only slightly stable, and has higher turbulence levels more characteristic of neutral flows. C3b and C3c had extremely low turbulence levels, and correspondingly low variances in the VAWT harmonic spikes. For these two cases, the VAWT $W_{S}$ simulation had only $5-10 \%$ as much variance as the HAWT simulation. Case $C 4$ had high wind speeds, very high vertical wind shears, and levels of turbulence similar to the neutral cases. The very high values of variance in the HAWT simulations for the stable cases are due to the rotation of the HAWT blade through large vertical wind shears. Even so, VAWT spike variance was $22-29 \%$ of HAWT variance.

\subsection{SPECTRAL ANALYSIS OF DATA CASES}

Spectral plots are in Figures 3-1 to 3-13. Wind speed spectra (parts a and $b$ of each figure) have been normalized by adjusting all the time series slightly so that they have the same mean wind speed at each anemometer location. This eliminates small differences in mean wind speed between anemometers, due mostly to measurement error. Even a mean wind speed error of $2 \%$, the expected accuracy of the Gi11 anemometers, will produce noticeable differences in the 

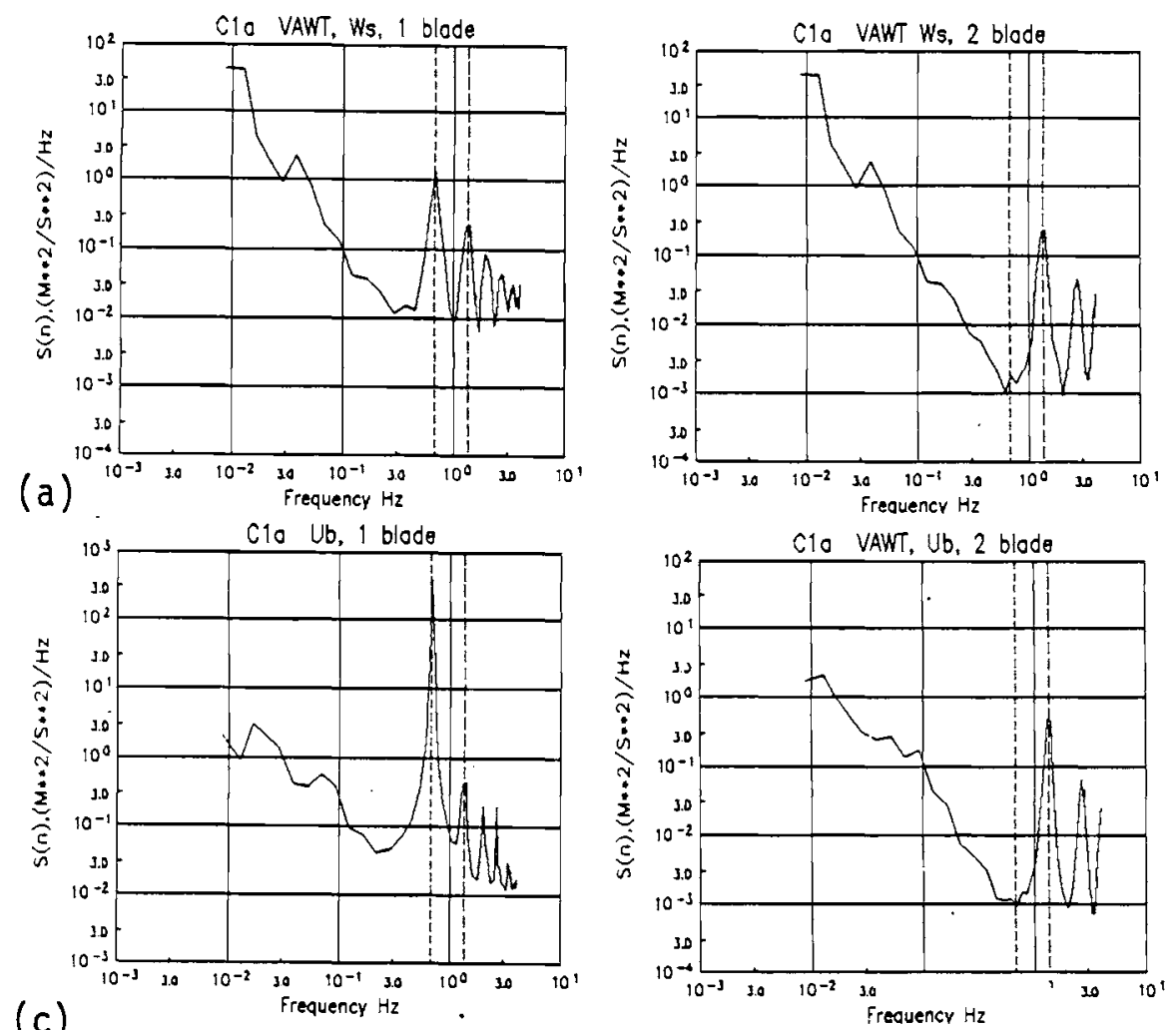

(b)
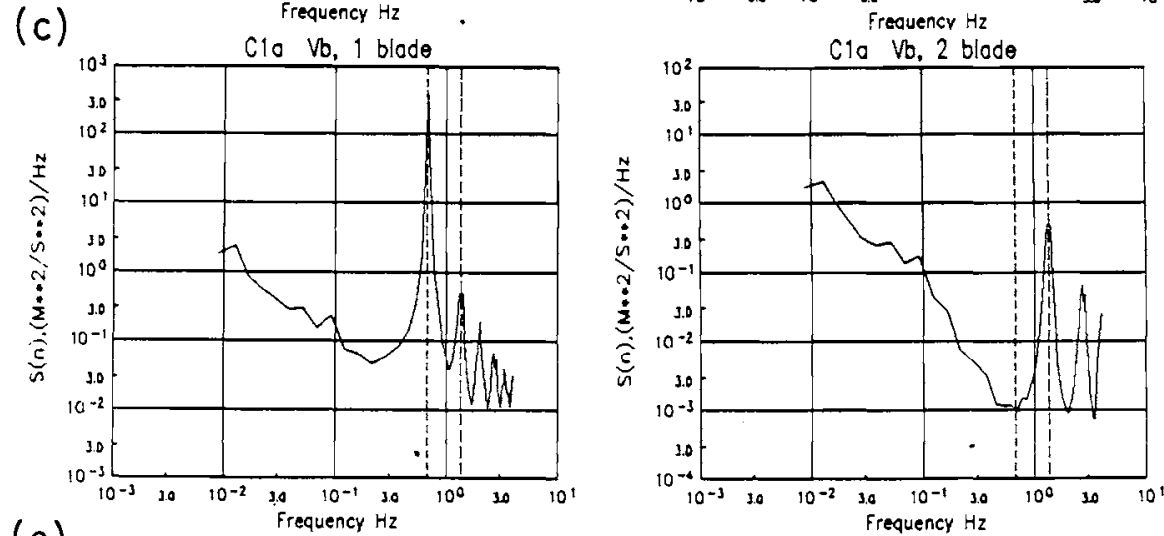

(d)
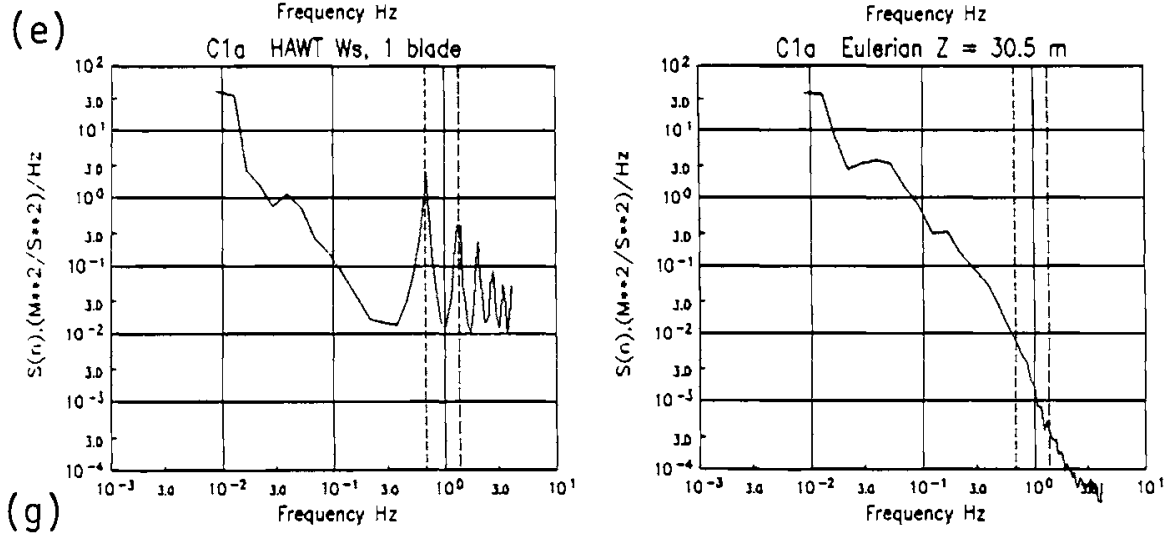

(f)

(h)

FIGURE 3-1. Complete Set of Spectral Plots for Case Cla, (a) $W_{S}, 1$ Blade (same as 4-5b), (b) $W_{s}, 2$ Blade (same as 4-5c), (c) $U_{b} 1$ Blade (same as 4-5d), (d) $U_{b}, 2$ Blade, (e) $V_{b}$, the Radial wind Component, for 1 Blade, ( $f$ ) $v_{b}, 2$ Blade, ( $g$ ) Wind Speed for the Horizontal Axis Wind Turbine Simulation, 1 Blade, (h) Eulerian or Fixed-Point Wind Speed (same as 4-5a). 

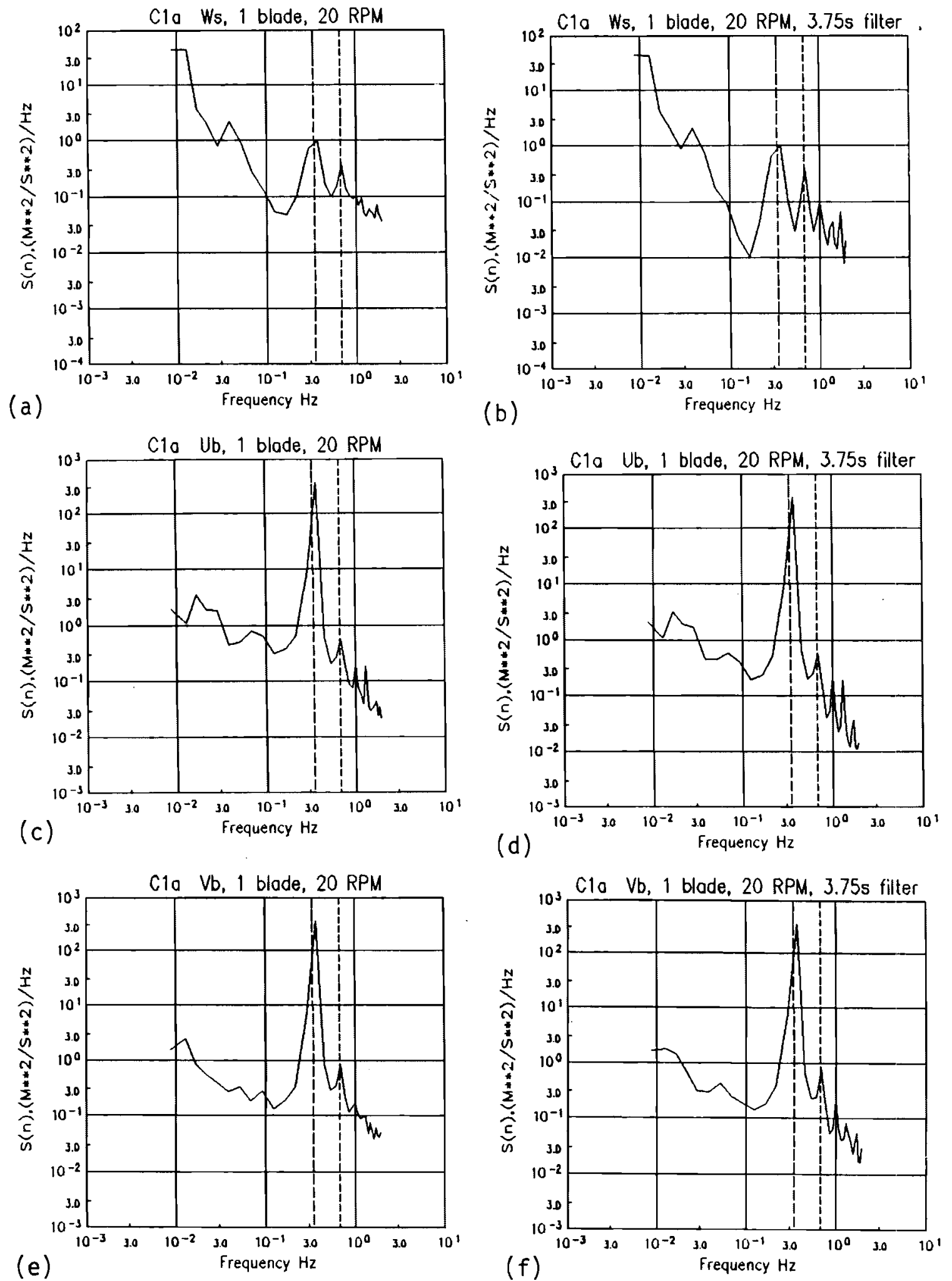

FIGURE 3-2. Spectral Plots of Case Cla, for a Simulated 20 RPM VAWT, (a) $W_{5}$ 1 Blade, Original Data, (b) $W_{5}, 1$ Blade Anemometer Data Filtered With a 15 Point (3.75 Second) Lowpass Filter Before Rotational Sampling, (c) $U_{b}, 1$ Blade, (d) $U_{b}, 1$ Blade 3.75 Second Filter, (e) $V_{b}, 1$ Blade, (f) $V_{b}, 1$ Blade, 3.75 Second Filter. 

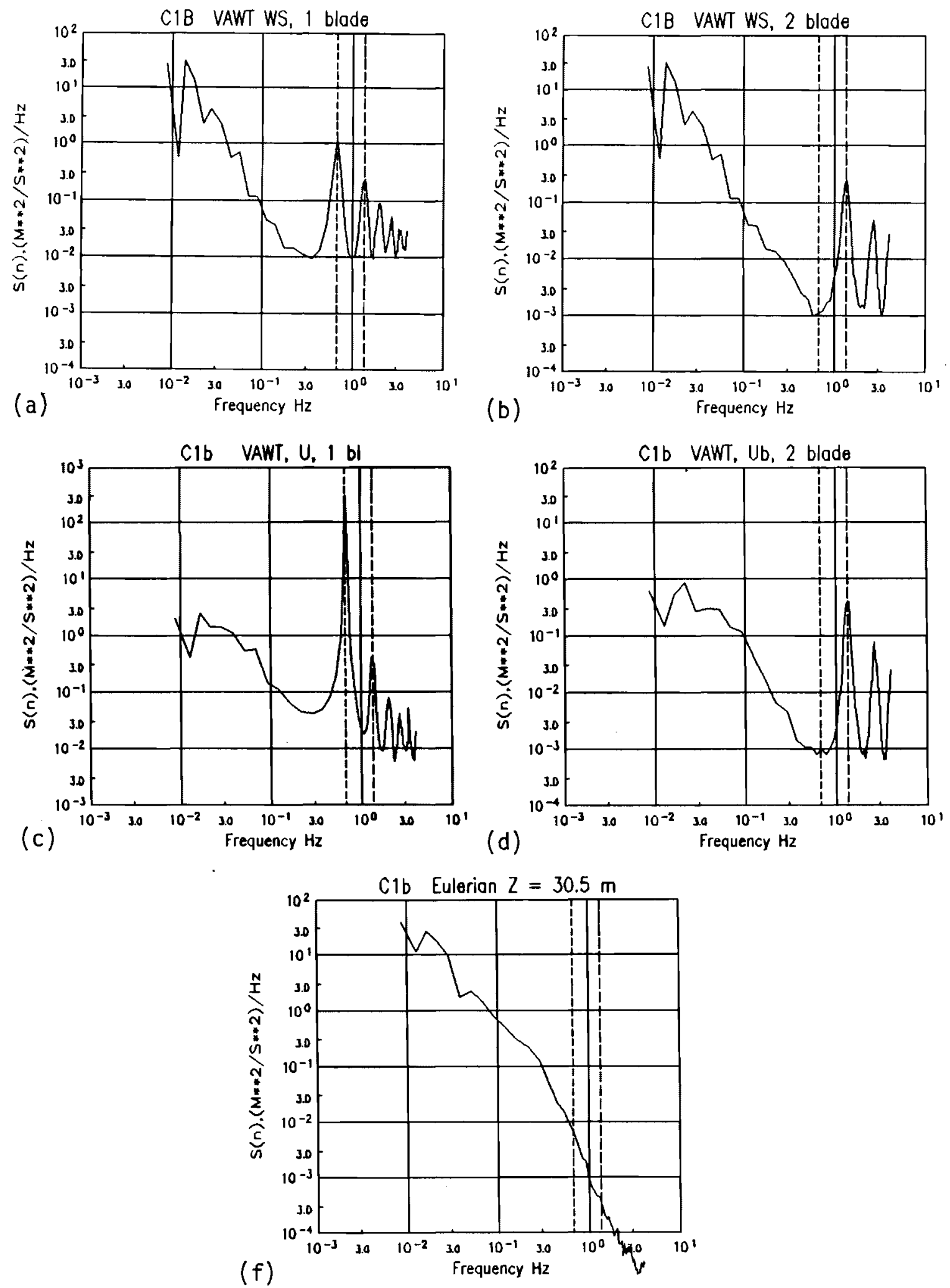

FIGURE 3-3. Spectral Plots for Case C1b. Vertical dashed lines mark the $1 P$ and $2 P$ frequencies. 

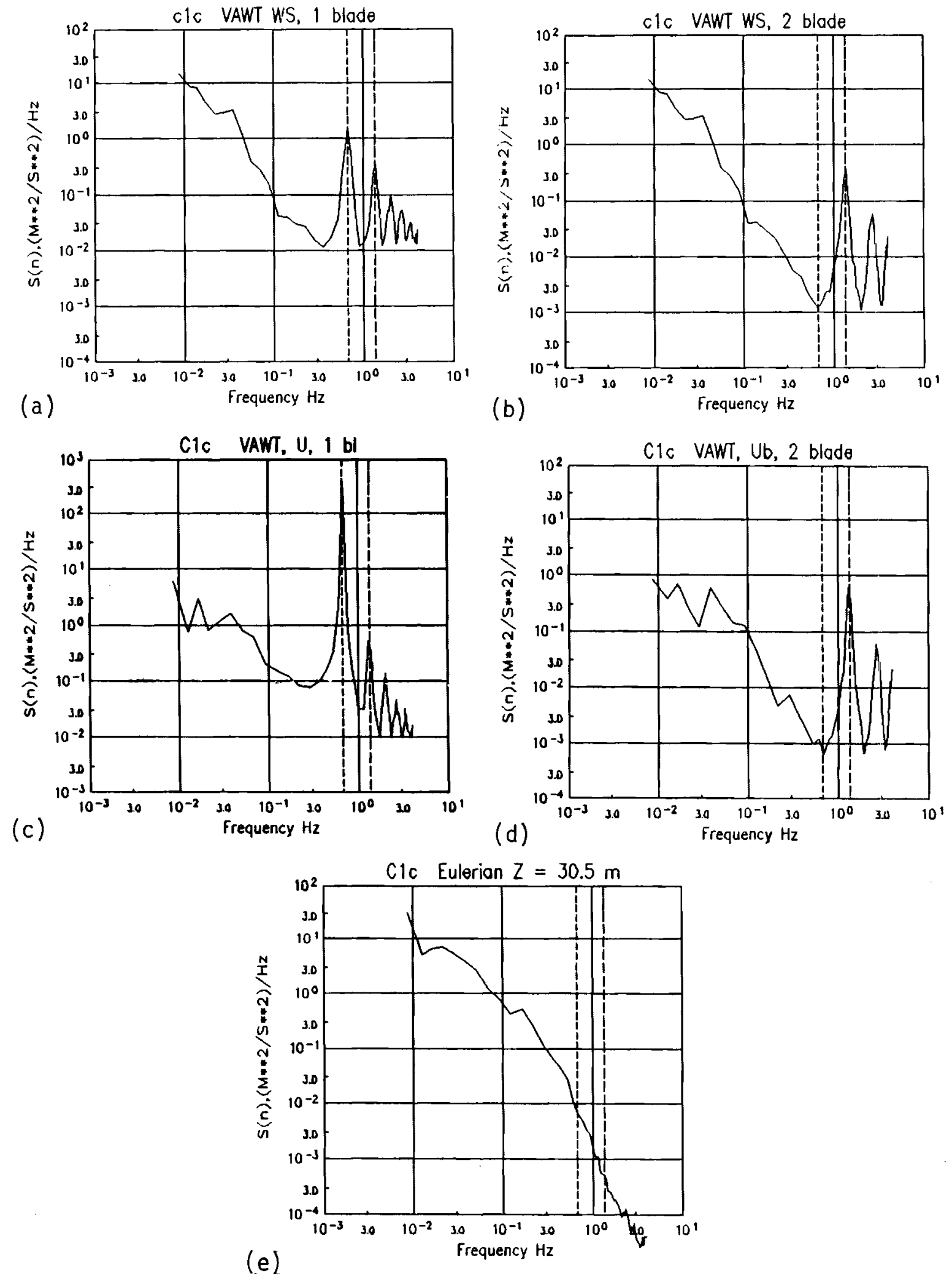

FIGURE 3-4. Spectral Plots for Case C1c. Vertical dashed lines mark the $1 P$ and $2 P$ frequencies. 

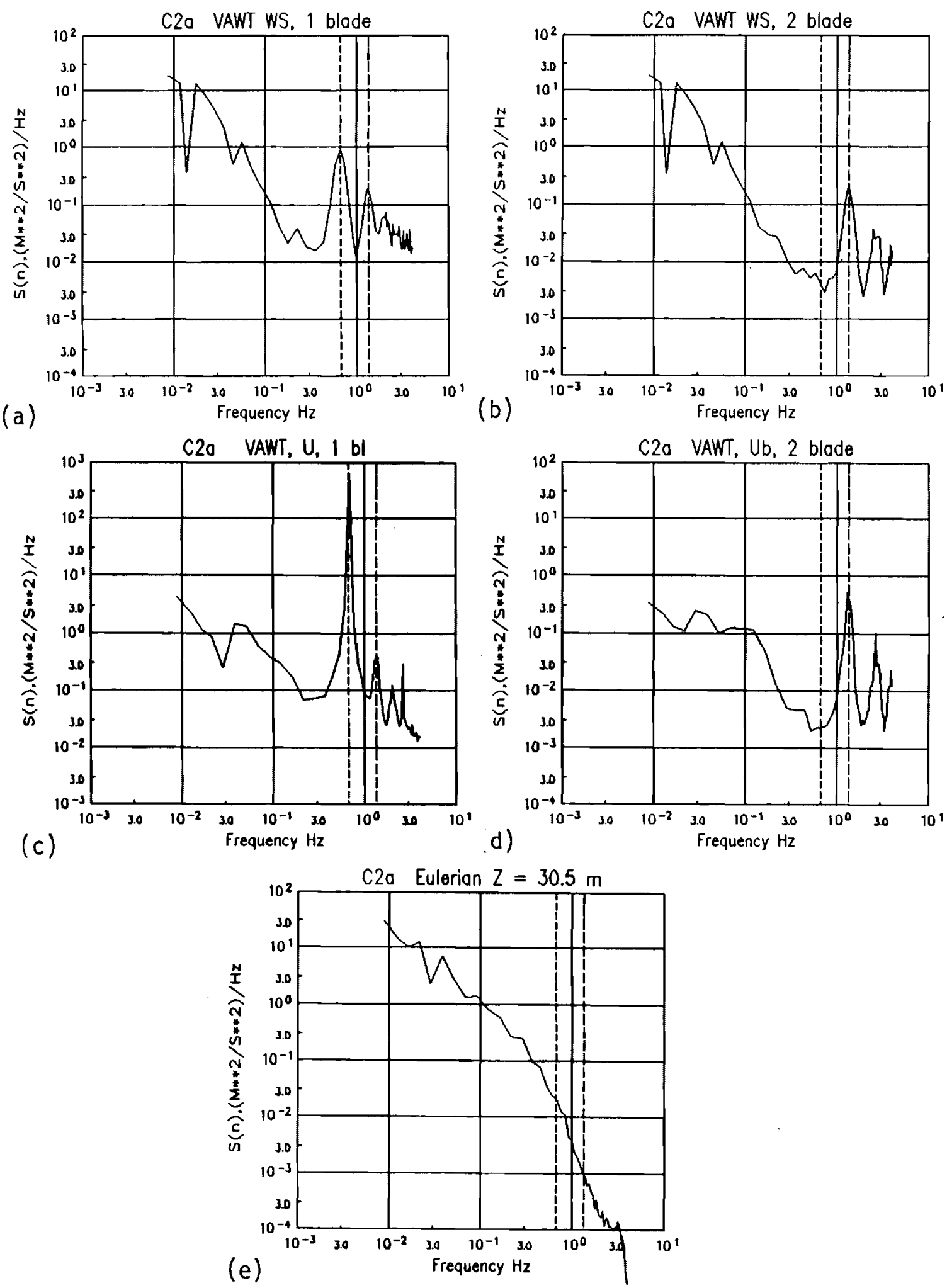

FIGURE 3-5. Spectral Plots for Case C2a. Vertical dashed lines mark the $1 P$ and $2 P$ frequencies. 

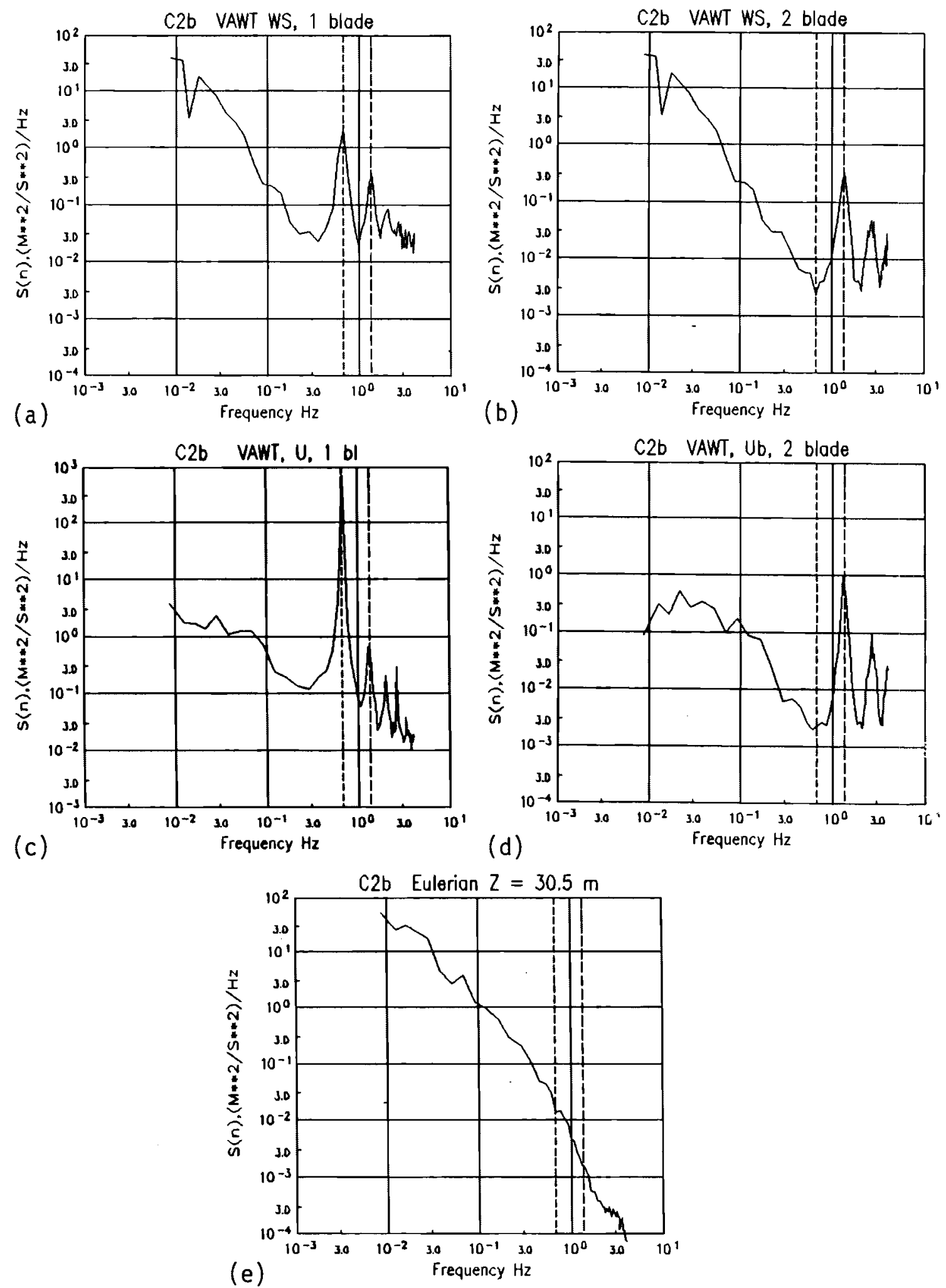

FIGURE 3-6. Spectral Plots for Case C2b. Vertical dashed lines mark the $1 P$ and $2 P$ frequencies. 

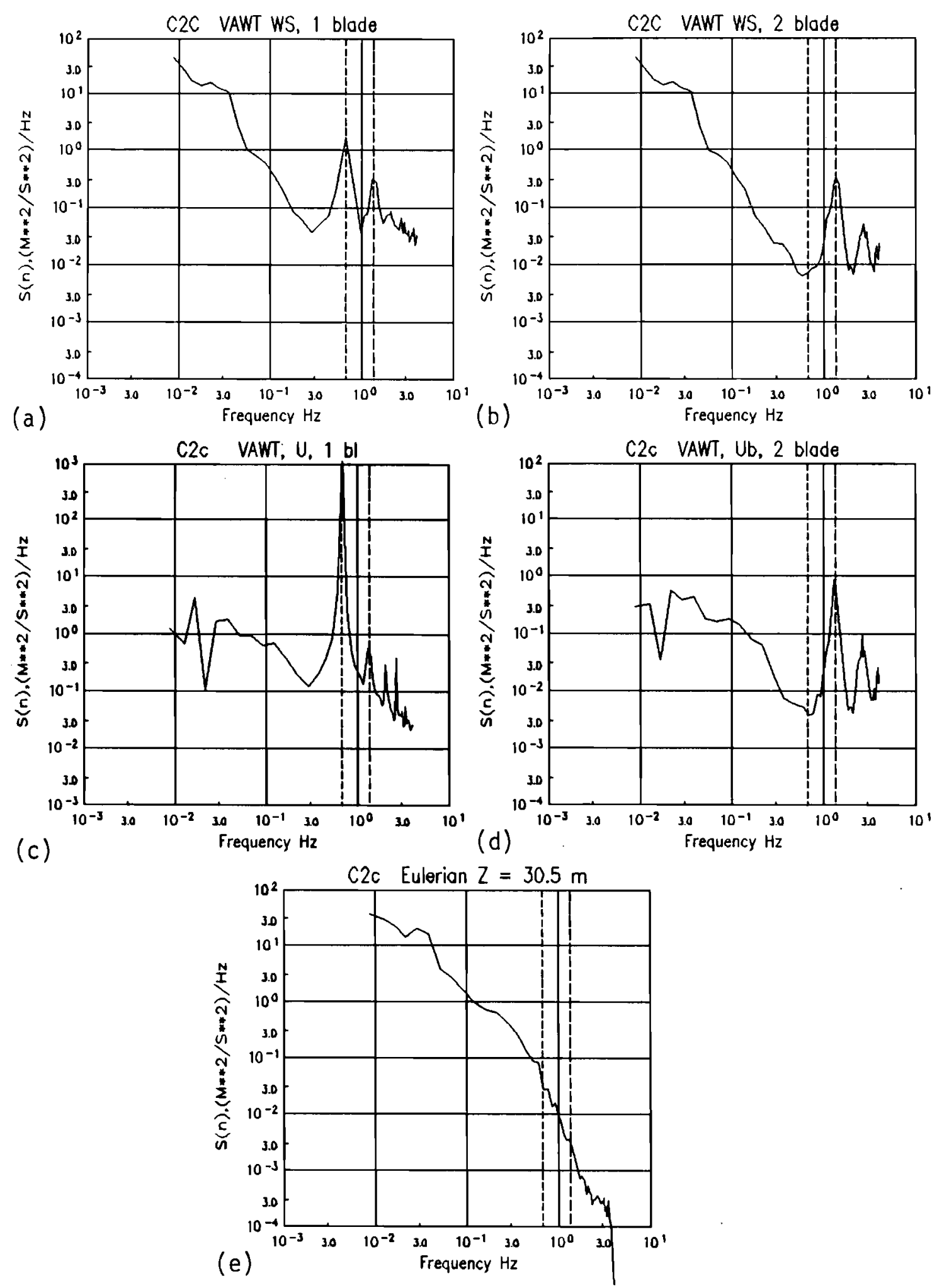

FIGURE 3-7. Spectral Plots for Case C2c. Vertical dashed lines mark the $1 P$ and $2 P$ frequencies. 

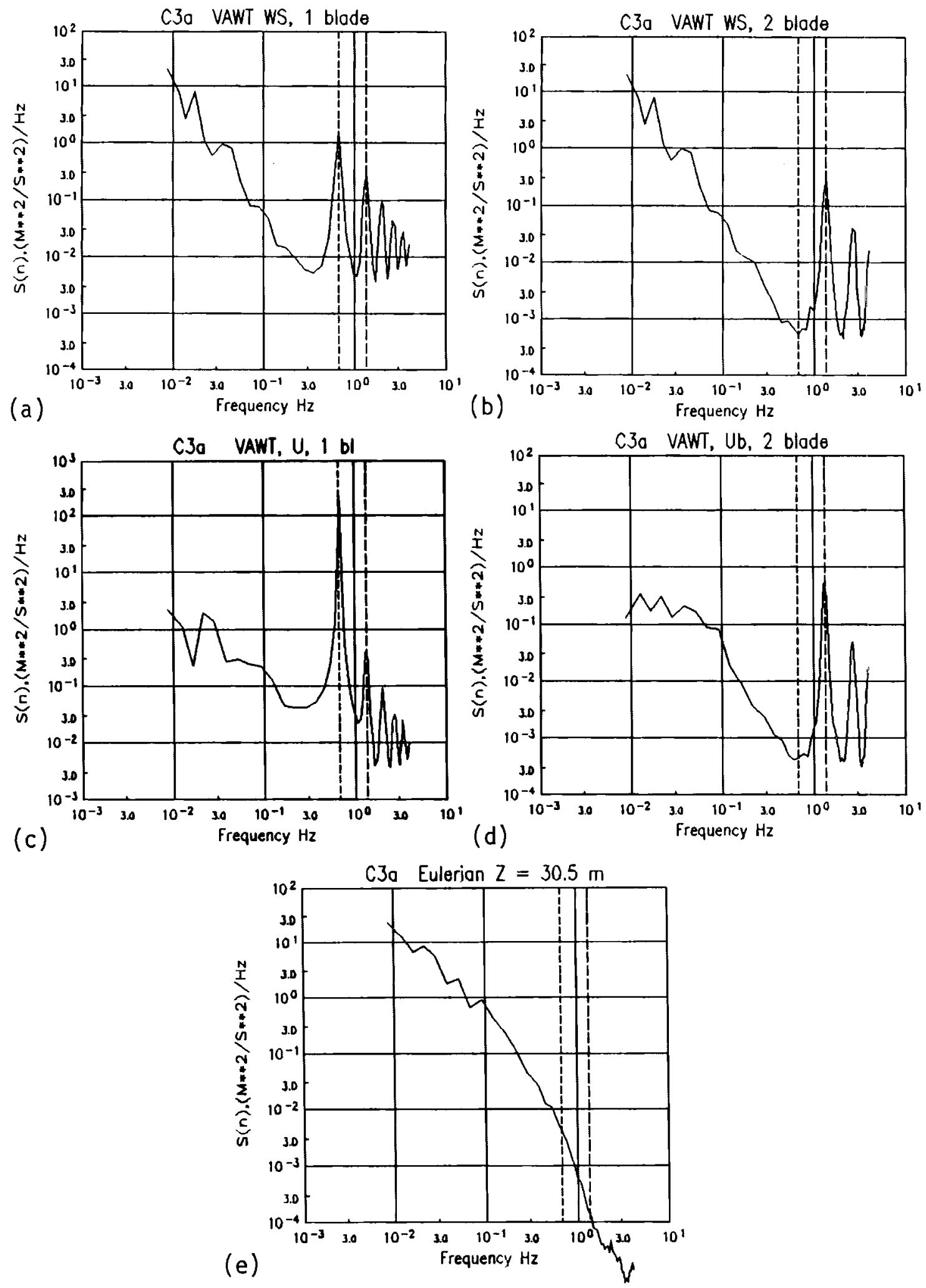

FIGURE 3-8. Spectral Plots for Case C3a. Vertical dashed lines mark the $1 P$ and $2 P$ frequencies. 

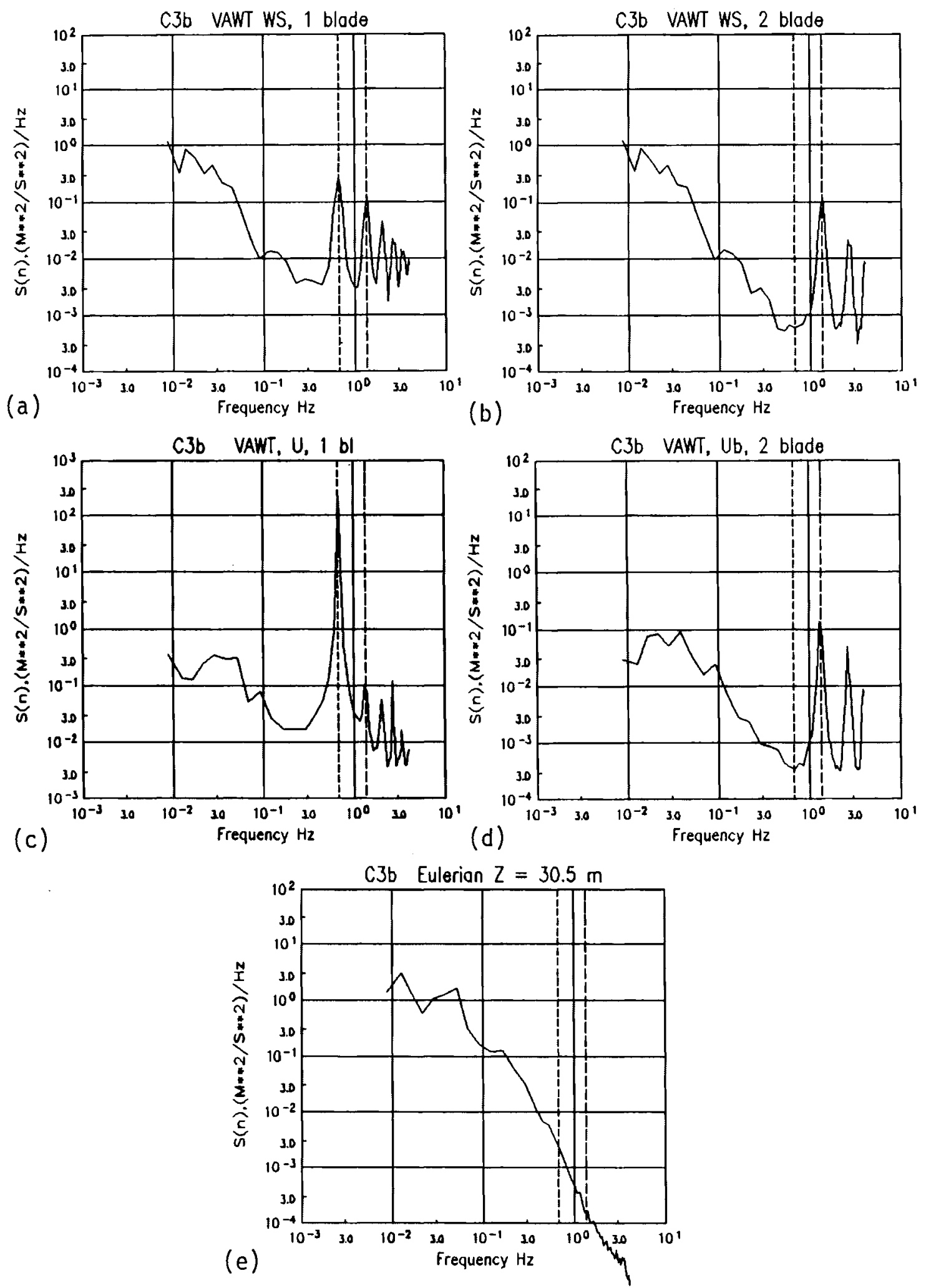

FIGURE 3-9. Spectral Plots for Case C3b. Vertical dashed lines mark the $1 P$ and $2 P$ frequencies. 

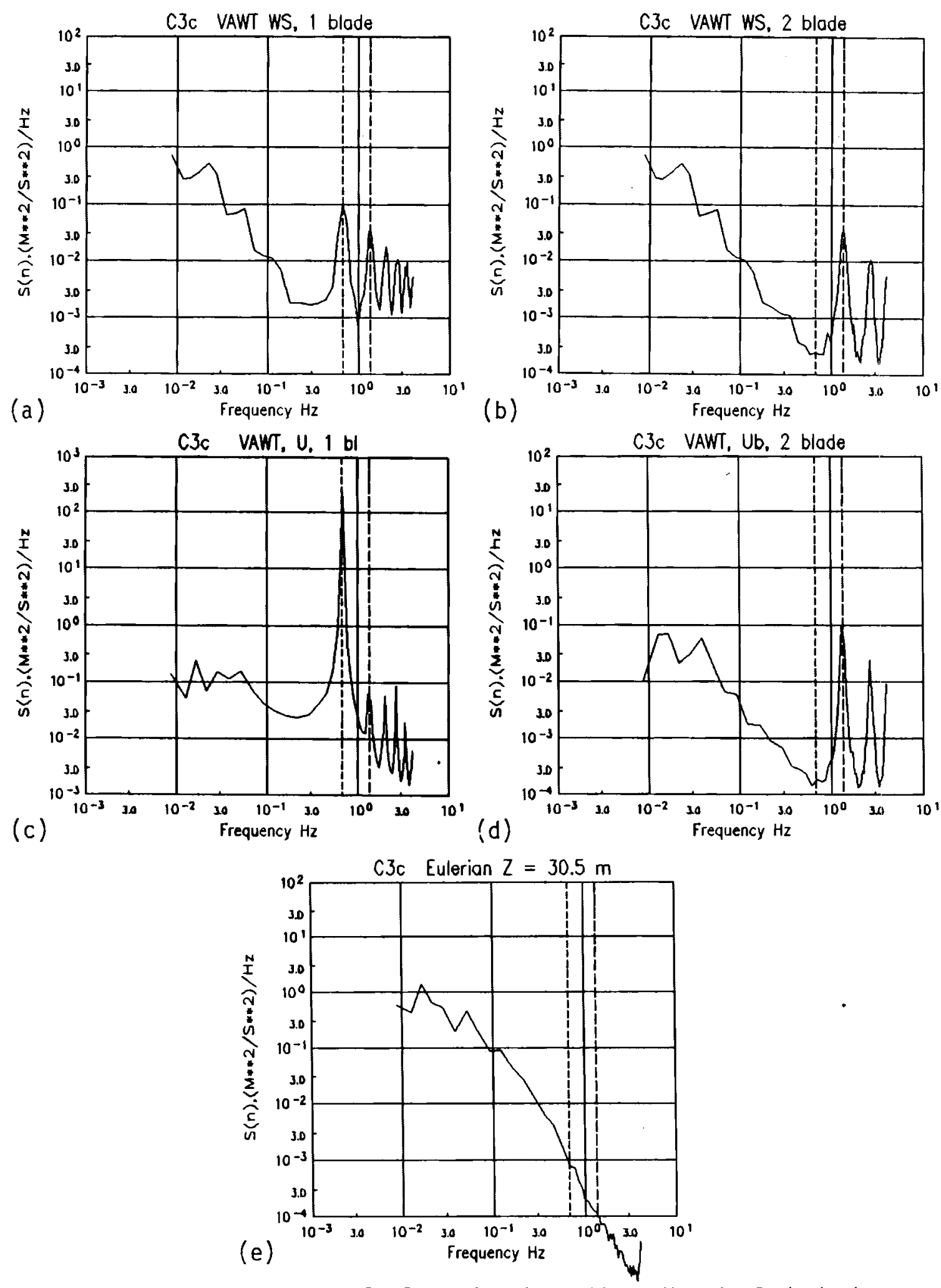

FIGURE 3-10. Spectral Plots for Case C3c. Vertical dashed lines mark the $1 P$ and $2 P$ frequencies. 

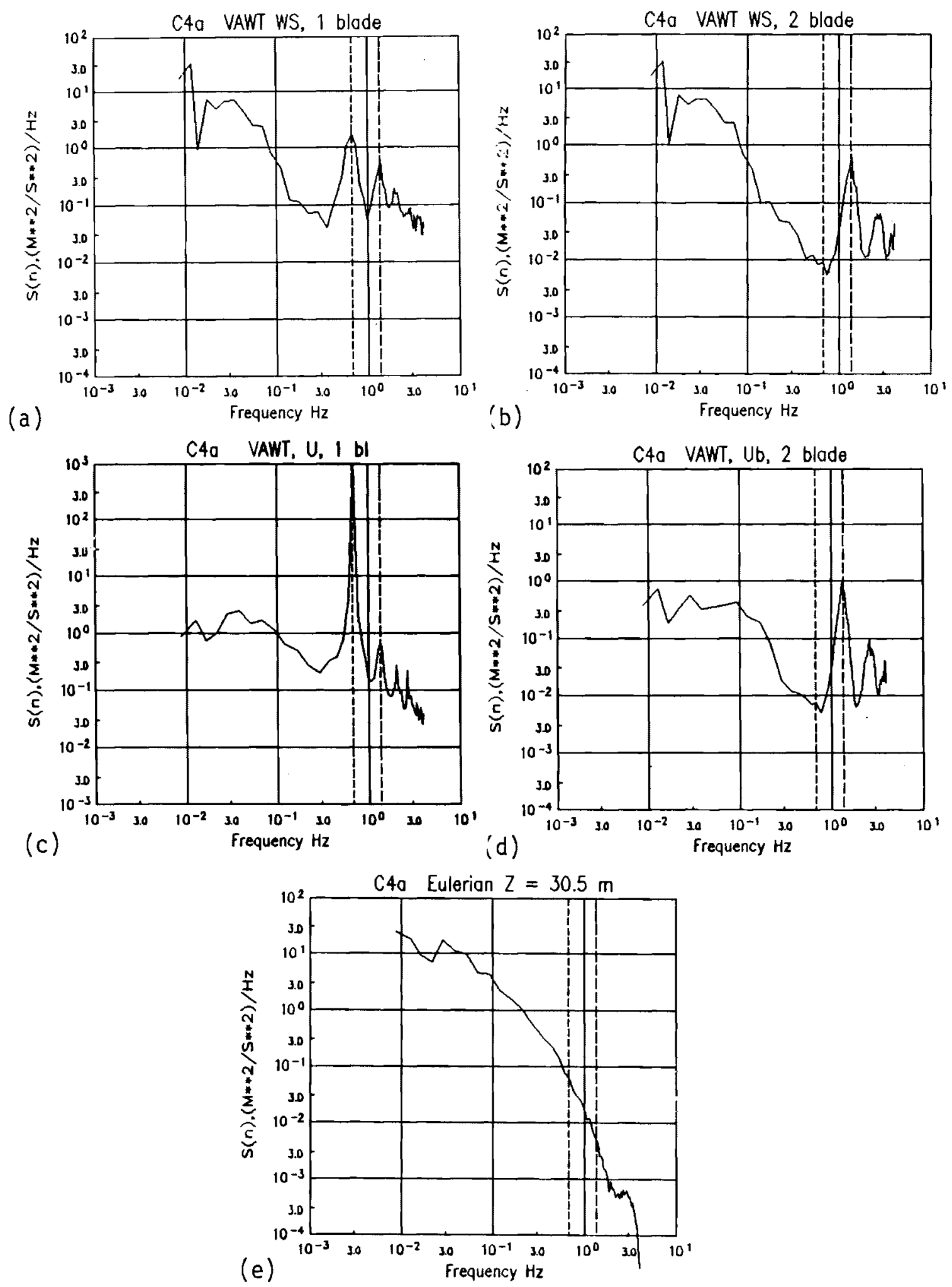

FIGURE 3-11. Spectral Plots for Case C4a. Vertical dashed lines mark the $1 P$ and $2 P$ frèquencies. 

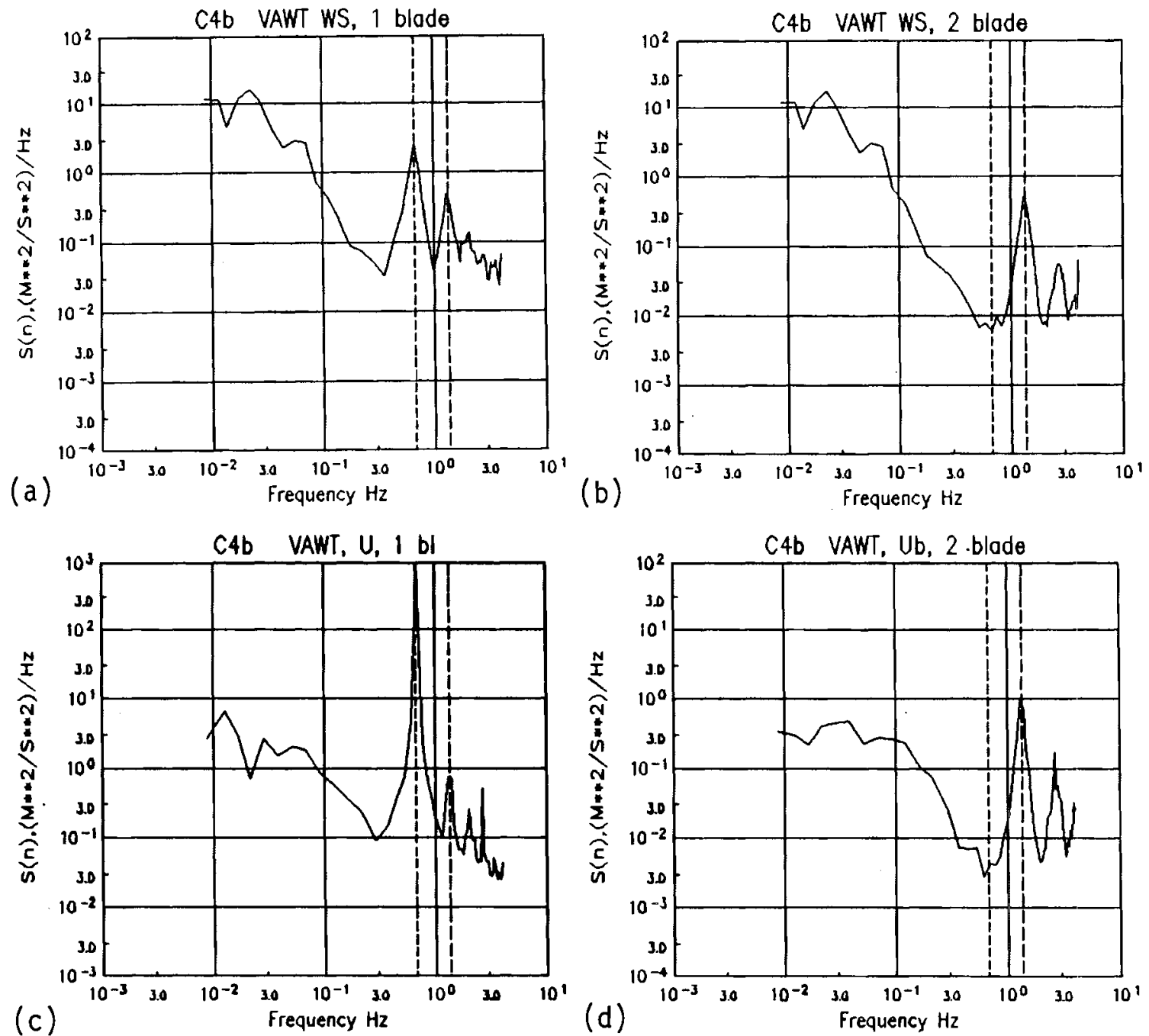

(d)

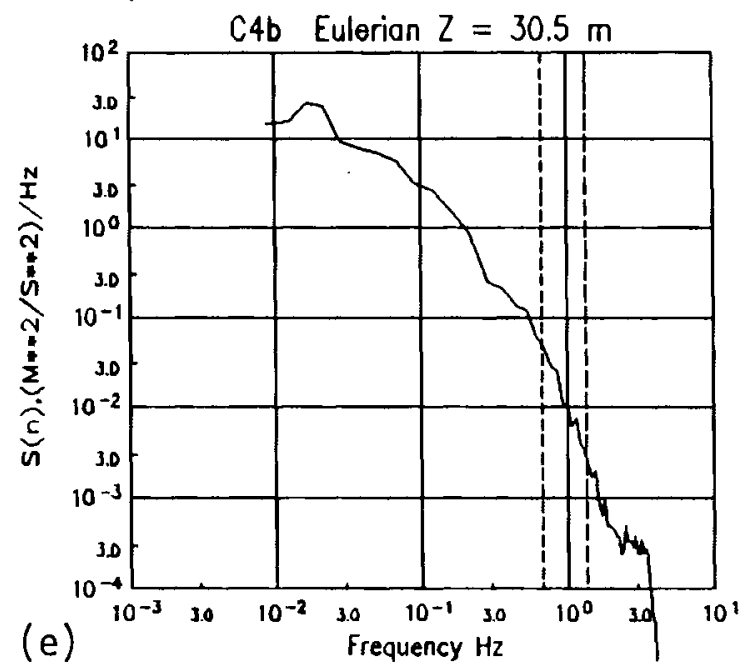

FIGURE 3-12. Spectral Plots for Case C4b. Vertical dashed lines mark the $1 P$ and $2 P$ frequencies. 

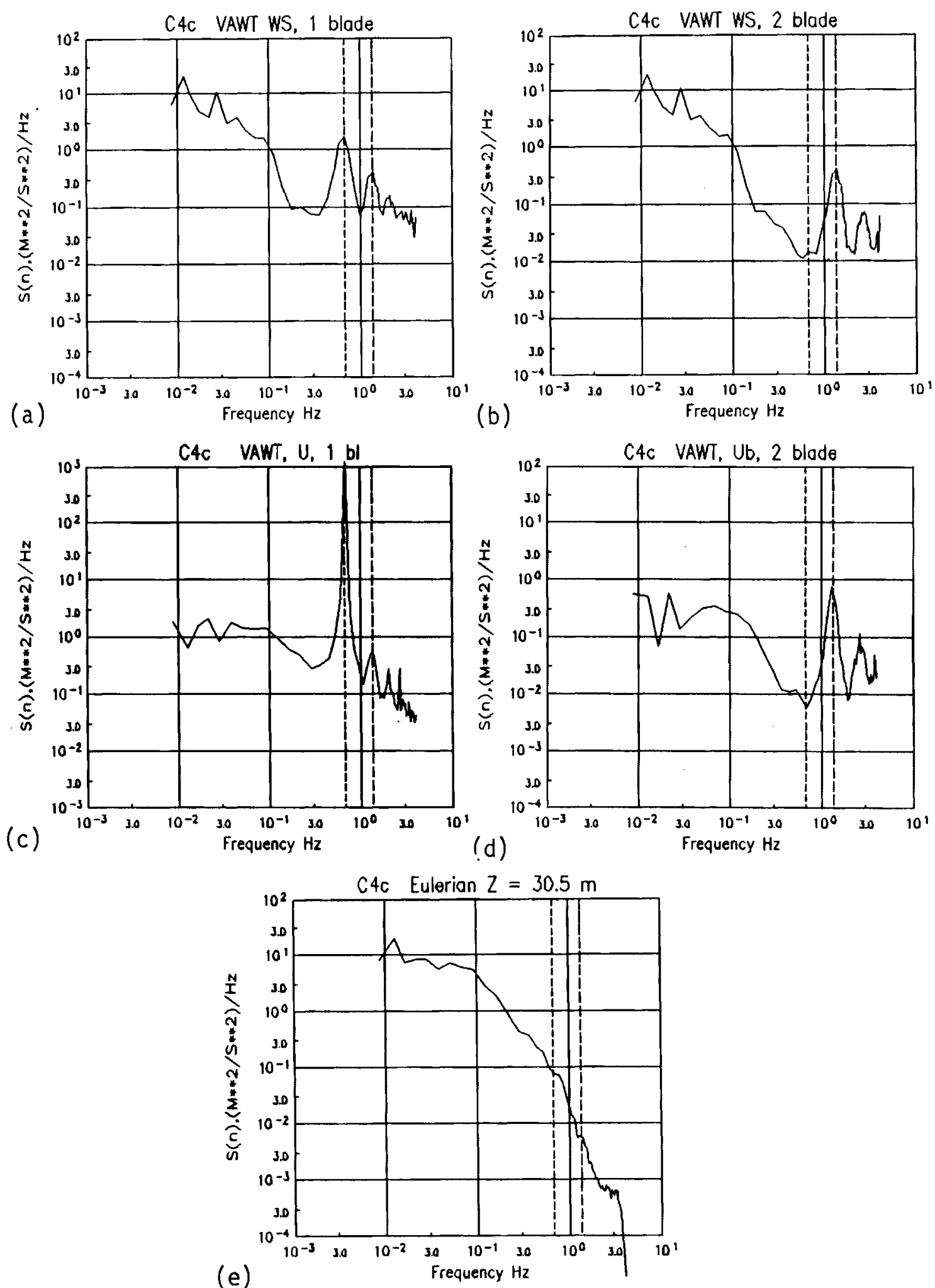

FIGURE 3-13. Spectral Plots for Case C4c. Vertical dashed lines mark the $1 P$ and $2 P$ frequencies. 
higher frequency spikes (4P and 5P). A similar smoothing of the vertical wind shear was used to produce the HAWT spectra. The VAWT Ub and Vb simulations were not similarly corrected.

A complete set of spectral plots for case Cla is given in Figure 3-1. Parts $a, b, c$ and $h$ were discussed in Chapter 2. The two-blade spectrum for Ub (Figure 3-1d) has somewhat higher spikes at $2 P$ and $4 P$ than the VAWT wind speed in Figure 3-1b. Spectra for $V_{b}$ are very similar to those for $U_{b}$. The HAWT spectrum in (Figure 3-1g) is only slightly different from the VAWT spectrum in 3-1a. It is smoother in the low frequencies, and it has sharper spikes, due to the presence of mean wind shear in this time series.

Data for the same time period were used to simulate VAWT rotation at 20 rpm. This cuts the tip speed ratio in half, to 5.2 in this case. As can be seen in Figure 3-2, this produces a spectrum with a different character than in the $40 \mathrm{rpm}$ case. Spectral peaks beyond $2 \mathrm{P}$ are not clearly resolved. Our experience with rotational sampling has shown that the level of the spectrum between spikes is related to the level of the Eulerian spectrum at the $1 \mathrm{P}$ frequency. For $20 \mathrm{rpm}$, the $1 \mathrm{P}$ frequency is $0.333 \mathrm{~Hz}$. Looking at Figure 3-1h, we see that the Eulerian spectrum is about one decade higher at $0.333 \mathrm{~Hz}$ than at $0.6667 \mathrm{~Hz}$. The level of the rotational spectrum between spikes (Figure 3-2a) is raised above the level in the 40 rpm case (Figure 3-1a) by about the same amount. This higher "noise" content in the simulated analysis can be removed by lowpass filtering of the data from each anemometer before the rotational sampling is performed. For the 20 rpm case, a lowpass filter was created on each anemometer by using a running mean of 15 consecutive data points, or 3.75 seconds of data. These heavily filtered data were then rotationally sampled using the VAWT simulation. The resulting spectrum for single blade wind speed, Figure $3-2 b$, looks much more like the 40 rpm spectrum (Figure 3-1a) than the original 20 rpm spectrum in 3-2a. This demonstrates that the characteristic harmonic spikes are due to relatively large turbulent wind eddies. The same effect is visible for the $U_{b}$ simulations (3-2c, unfiltered and $3-2 d, f i l t e r e d)$ and the $V_{b}$ simulations $(3-2 e$ and $f)$.

For the remainder of the 12 data cases, an abbreviated set of five spectral plots is presented. These plots are for $40 \mathrm{rpm}$ simulations only, in 
Figures 3-3 to 3-13. This set includes spectra of $W_{s}$ for one-blade and two-blade simulations, $U_{b}$ for one-blade and two-blade simulations, and the Eulerian spectrum. The remaining neutral low-wind speed cases, cases Clb and $\mathrm{Clc}$, look remarkably similar to case $\mathrm{Cla}$.

In case $\mathrm{C} 2$, higher wind speed neutral-to-unstable cases, the character of the spectra is somewhat different. Higher frequency peaks are not clearly resolved in the one-blade $w_{s}$ case (Figures $3-5 a, 3-6 a, 3-7 a$ ). This can be related to the Eulerian spectrum in the same way that the $20 \mathrm{rpm}$ and the $40 \mathrm{rpm}$ spectra were related. Once again, the level of the Eulerian spectrum at the $1 P$ frequency is close to the level of the $4 P$ and $5 P$ spikes, making the spikes more difficult to resolve. The spikes themselves seem to be broader in case $\mathrm{C} 2$ than in $\mathrm{C} 1$, for one-blade and two-blade wind speed spectra.

A somewhat objective way to compare these rotational spectra to one another is to compile a table of the integrated spectral spikes, as detailed in the previous chapter. In Tables 3-2 and 3-3, we present al1 the $\sigma_{i}{ }^{2} s$, where $i=0$ (low frequency) to 5 ( $5 \mathrm{P}$ spike), for all 12 cases, and $W_{S}, U_{b}$, and $V_{b}$ for both one-blade and two-blade simulations. In Table 3-2, the spike variances for $\mathrm{Cl}$ and $\mathrm{C2}$, the neutral-to-unstable cases, are shown. The 1arge differences in low frequency variance from one case to the next are due to differences in stationarity between the various cases. The variance due to the large $1 P$ spike in $U_{b}$ and $V_{b}$ one-blade simulations is approximately $(\sqrt{2} / 2 X$ mean $\left.w_{s}\right)^{2}$, or the variance of a sine wave with amplitude of the mean wind speed.

The next three figures (3-8 to $3-10)$ show case $\mathrm{C3}$, the nighttime stable low wind case. For all these cases, the dips between spikes are much lower than any in cases $\mathrm{C} 1$ and $\mathrm{C} 2$. Case $\mathrm{C} 3 \mathrm{a}$, which was only slightly stable, looks similar to case $\mathrm{C} 1$. However, $\mathrm{C} 3 \mathrm{~b}$ and $\mathrm{C} 3 \mathrm{c}$ have very weak spikes in the wind speeds ( $1 P$ to $5 P$ ) and the blade-relative winds (2P to $5 P$ ). This is due to the near absence of turbulence in the wind for these two cases. However, the basic 5-spike structure is evident for all the cases.

In contrast, the high wind speed stable cases, in C4 (Figures 3-11 to $3-13)$ have higher levels of turbulence than the neutral cases. When 
TABLE 3-2. Variance in Each Spike, Cases C1 and C2

\begin{tabular}{|c|c|c|c|c|c|c|c|}
\hline $\begin{array}{l}\text { Simulation } \\
\text { Type }\end{array}$ & & Cla & Clb & $\begin{array}{l}\text { e Num } \\
\text { Clc }\end{array}$ & C $2 a$ & $\mathrm{C} 2 \mathrm{~b}$ & $\mathrm{C} 2 \mathrm{c}$ \\
\hline $\begin{array}{l}\text { VAWT } \\
\text { Ws } \\
\text { I Blade }\end{array}$ & $\begin{array}{l}\text { Lo Freq } \\
\text { IP } \\
2 \mathrm{P} \\
3 \mathrm{P} \\
4 \mathrm{P} \\
5 \mathrm{P}\end{array}$ & $\begin{array}{l}0.888 \\
0.157 \\
0.063 \\
0.029 \\
0.019 \\
0.017\end{array}$ & $\begin{array}{l}1.043 \\
0.149 \\
0.054 \\
0.030 \\
0.016 \\
0.013\end{array}$ & $\begin{array}{l}0.346 \\
0.186 \\
0.068 \\
0.031 \\
0.022 \\
0.015\end{array}$ & $\begin{array}{l}0.375 \\
0.173 \\
0.058 \\
0.033 \\
0.021 \\
0.015\end{array}$ & $\begin{array}{l}0.818 \\
0.274 \\
0.082 \\
0.037 \\
0.023 \\
0.018\end{array}$ & $\begin{array}{l}0.777 \\
0.276 \\
0.108 \\
0.044 \\
0.032 \\
0.023\end{array}$ \\
\hline $\begin{array}{l}\text { VAWT } \\
\text { Ub } \\
\text { I Blade }\end{array}$ & $\begin{array}{l}\text { Lo Freq } \\
\text { IP } \\
2 \mathrm{P} \\
3 \mathrm{P} \\
4 \mathrm{P} \\
5 \mathrm{P}\end{array}$ & $\begin{array}{r}0.104 \\
30.058 \\
0.097 \\
0.036 \\
0.027 \\
0.012\end{array}$ & $\begin{array}{r}0.093 \\
23.844 \\
0.071 \\
0.022 \\
0.013 \\
0.010\end{array}$ & $\begin{array}{r}0.136 \\
29.722 \\
0.088 \\
0.031 \\
0.016 \\
0.011\end{array}$ & $\begin{array}{r}0.124 \\
49.269 \\
0.097 \\
0.038 \\
0.040 \\
0.013\end{array}$ & $\begin{array}{r}0.183 \\
56.472 \\
0.119 \\
0.044 \\
0.039 \\
0.014\end{array}$ & $\begin{array}{r}0.186 \\
94.018 \\
0.158 \\
0.065 \\
0.054 \\
0.022\end{array}$ \\
\hline $\begin{array}{l}\text { VAWT } \\
\text { Vb } \\
1 \text { Blade }\end{array}$ & $\begin{array}{l}\text { Lo Freq } \\
\text { IP } \\
2 \mathrm{P} \\
3 \mathrm{P} \\
4 \mathrm{P} \\
5 \mathrm{P}\end{array}$ & $\begin{array}{r}0.060 \\
29.381 \\
0.106 \\
0.036 \\
0.022 \\
0.014\end{array}$ & $\begin{array}{r}0.036 \\
23.620 \\
0.093 \\
0.034 \\
0.024 \\
0.018\end{array}$ & $\begin{array}{r}0.040 \\
29.467 \\
0.112 \\
0.045 \\
0.023 \\
0.026\end{array}$ & $\begin{array}{r}0.047 \\
48.255 \\
0.117 \\
0.043 \\
0.027 \\
0.019\end{array}$ & $\begin{array}{r}0.042 \\
55.817 \\
0.180 \\
0.060 \\
0.032 \\
0.021\end{array}$ & $\begin{array}{r}0.079 \\
91.756 \\
0.187 \\
0.081 \\
0.040 \\
0.025\end{array}$ \\
\hline $\begin{array}{l}\text { VAWT } \\
\text { Ws } \\
2 \text { Blade }\end{array}$ & $\begin{array}{l}\text { Lo Freq } \\
\text { IP } \\
2 \mathrm{P} \\
3 \mathrm{P} \\
4 \mathrm{P} \\
5 \mathrm{P}\end{array}$ & $\begin{array}{l}0.885 \\
0.002 \\
0.061 \\
0.002 \\
0.018 \\
0.002\end{array}$ & $\begin{array}{l}1.045 \\
0.001 \\
0.054 \\
0.002 \\
0.015 \\
0.001\end{array}$ & $\begin{array}{l}0.347 \\
0.002 \\
0.066 \\
0.002 \\
0.020 \\
0.002\end{array}$ & $\begin{array}{l}0.374 \\
0.004 \\
0.056 \\
0.004 \\
0.018 \\
0.004\end{array}$ & $\begin{array}{l}0.824 \\
0.004 \\
0.076 \\
0.004 \\
0.020 \\
0.005\end{array}$ & $\begin{array}{l}0.772 \\
0.007 \\
0.099 \\
0.008 \\
0.022 \\
0.009\end{array}$ \\
\hline $\begin{array}{l}\text { VAWT } \\
\text { Ub } \\
2 \text { Blade }\end{array}$ & $\begin{array}{l}\text { Lo Freq } \\
\text { IP } \\
2 \mathrm{P} \\
3 \mathrm{P} \\
4 \mathrm{P} \\
5 \mathrm{P}\end{array}$ & $\begin{array}{l}0.093 \\
0.001 \\
0.080 \\
0.001 \\
0.023 \\
0.002\end{array}$ & $\begin{array}{l}0.083 \\
0.001 \\
0.068 \\
0.001 \\
0.011 \\
0.001\end{array}$ & $\begin{array}{l}0.117 \\
0.001 \\
0.081 \\
0.001 \\
0.014 \\
0.001\end{array}$ & $\begin{array}{l}0.106 \\
0.003 \\
0.072 \\
0.002 \\
0.033 \\
0.003\end{array}$ & $\begin{array}{l}0.150 \\
0.004 \\
0.105 \\
0.003 \\
0.034 \\
0.003\end{array}$ & $\begin{array}{l}0.155 \\
0.006 \\
0.108 \\
0.006 \\
0.041 \\
0.006\end{array}$ \\
\hline $\begin{array}{l}\text { VAWT } \\
\text { Vb } \\
2 \text { Blade }\end{array}$ & $\begin{array}{l}\text { Lo Ereq } \\
\text { IP } \\
2 \mathrm{P} \\
3 \mathrm{P} \\
4 \mathrm{P} \\
5 \mathrm{P}\end{array}$ & $\begin{array}{l}0.045 \\
0.001 \\
0.091 \\
0.001 \\
0.019 \\
0.001\end{array}$ & $\begin{array}{l}0.033 \\
0.001 \\
0.079 \\
0.001 \\
0.019 \\
0.001\end{array}$ & $\begin{array}{l}0.037 \\
0.001 \\
0.089 \\
0.001 \\
0.018 \\
0.002\end{array}$ & $\begin{array}{l}0.025 \\
0.002 \\
0.097 \\
0.003 \\
0.022 \\
0.004\end{array}$ & $\begin{array}{l}0.036 \\
0.002 \\
0.142 \\
0.003 \\
0.023 \\
0.004\end{array}$ & $\begin{array}{l}0.040 \\
0.005 \\
0.150 \\
0.006 \\
0.028 \\
0.007\end{array}$ \\
\hline
\end{tabular}

compared to a neutral case with a similar wind speed ( $C 2 c$, Figure 3-7), the spikes look broader, and the "floor" to which the dips between spikes drops is higher. The tabulation of $\sigma_{i}{ }^{2}$ values for cases $\mathrm{C} 3$ and $\mathrm{C4}$ (Table 3-3) demonstrates the higher levels of turbulence in case $C 4$ and the very low levels in C3. Variance values for C4 are higher than C2c for practically all spikes and all simulation types.

We may wish to generalize the relationships among the various spectra as an aid in the practical application of these results. One parameter of 
TABLE 3-3. Variance in Each Spike, Cases C3 and C4

\begin{tabular}{|c|c|c|c|c|c|c|c|}
\hline $\begin{array}{c}\text { Simulation } \\
\text { Type }\end{array}$ & & C3a & c3b & $\begin{array}{l}\text { ase Num } \\
\text { C } 3 \mathrm{c}\end{array}$ & $\mathrm{C} 4 \mathrm{a}$ & $\mathrm{C} 4 \mathrm{~b}$ & $\mathrm{C} 4 \mathrm{C}$ \\
\hline $\begin{array}{l}\text { VAWT } \\
\text { Ws } \\
1 \text { Blade }\end{array}$ & $\begin{array}{l}\text { Lo Freg } \\
\text { IP } \\
2 \mathrm{P} \\
3 \mathrm{P} \\
4 \mathrm{P} \\
5 \mathrm{P}\end{array}$ & $\begin{array}{l}0.293 \\
0.156 \\
0.050 \\
0.025 \\
0.015 \\
0.010\end{array}$ & $\begin{array}{l}0.034 \\
0.035 \\
0.022 \\
0.011 \\
0.008 \\
0.006\end{array}$ & $\begin{array}{l}0.040 \\
0.015 \\
0.007 \\
0.005 \\
0.004 \\
0.003\end{array}$ & $\begin{array}{l}0.492 \\
0.370 \\
0.164 \\
0.083 \\
0.047 \\
0.036\end{array}$ & $\begin{array}{l}0.798 \\
0.396 \\
0.140 \\
0.062 \\
0.035 \\
0.028\end{array}$ & $\begin{array}{l}0.430 \\
0.397 \\
0.157 \\
0.077 \\
0.048 \\
0.043\end{array}$ \\
\hline $\begin{array}{l}\text { VAWT } \\
\text { Ub } \\
1 \text { Blade }\end{array}$ & $\begin{array}{l}\text { Lo Freq } \\
\text { IP } \\
2 \mathrm{P} \\
3 \mathrm{P} \\
4 \mathrm{P} \\
5 \mathrm{P}\end{array}$ & $\begin{array}{r}0.090 \\
18.020 \\
0.066 \\
0.019 \\
0.011 \\
0.008\end{array}$ & $\begin{array}{r}0.024 \\
17.601 \\
0.024 \\
0.013 \\
0.014 \\
0.005\end{array}$ & $\begin{array}{r}0.016 \\
16.455 \\
0.014 \\
0.009 \\
0.010 \\
0.004\end{array}$ & $\begin{array}{r}0.234 \\
77.145 \\
0.179 \\
0.077 \\
0.053 \\
0.029\end{array}$ & $\begin{array}{r}0.250 \\
76.176 \\
0.183 \\
0.073 \\
0.069 \\
0.022\end{array}$ & $\begin{array}{r}0.261 \\
96.654 \\
0.186 \\
0.086 \\
0.060 \\
0.032\end{array}$ \\
\hline $\begin{array}{l}\text { VAWT } \\
\text { Vb } \\
1 \text { Blade }\end{array}$ & $\begin{array}{l}\text { Lo Freq } \\
\text { IP } \\
2 \mathrm{P} \\
3 \mathrm{P} \\
4 \mathrm{P} \\
5 \mathrm{P}\end{array}$ & $\begin{array}{r}0.019 \\
17.782 \\
0.089 \\
0.030 \\
0.017 \\
0.014\end{array}$ & $\begin{array}{r}0.012 \\
17.246 \\
0.027 \\
0.014 \\
0.010 \\
0.007\end{array}$ & $\begin{array}{r}0.007 \\
16.058 \\
0.022 \\
0.009 \\
0.006 \\
0.004\end{array}$ & $\begin{array}{r}0.087 \\
79.825 \\
0.252 \\
0.111 \\
0.058 \\
0.038\end{array}$ & $\begin{array}{r}0.088 \\
76.168 \\
0.227 \\
0.088 \\
0.052 \\
0.031\end{array}$ & $\begin{array}{r}0.085 \\
99.458 \\
0.244 \\
0.107 \\
0.065 \\
0.041\end{array}$ \\
\hline $\begin{array}{l}\text { VAWT } \\
\text { Ws } \\
2 \text { Blade }\end{array}$ & $\begin{array}{l}\text { Lo Freq } \\
\text { IP } \\
2 \mathrm{P} \\
3 \mathrm{P} \\
4 \mathrm{P} \\
5 \mathrm{P}\end{array}$ & $\begin{array}{l}0.293 \\
0.001 \\
0.049 \\
0.001 \\
0.014 \\
0.001\end{array}$ & $\begin{array}{l}0.034 \\
0.001 \\
0.021 \\
0.001 \\
0.007 \\
0.001\end{array}$ & $\begin{array}{l}0.040 \\
0.000 \\
0.007 \\
0.000 \\
0.004 \\
0.000\end{array}$ & $\begin{array}{l}0.484 \\
0.008 \\
0.157 \\
0.011 \\
0.034 \\
0.012\end{array}$ & $\begin{array}{l}0.799 \\
0.007 \\
0.135 \\
0.008 \\
0.027 \\
0.009\end{array}$ & $\begin{array}{l}0.427 \\
0.013 \\
0.147 \\
0.013 \\
0.037 \\
0.013\end{array}$ \\
\hline $\begin{array}{l}\text { VAWT } \\
\text { Ub } \\
2 \text { Blade }\end{array}$ & $\begin{array}{l}\text { Lo Freq } \\
\text { 1P } \\
2 \mathrm{P} \\
3 \mathrm{P} \\
4 \mathrm{P} \\
5 \mathrm{P}\end{array}$ & $\begin{array}{l}0.080 \\
0.001 \\
0.060 \\
0.001 \\
0.010 \\
0.001\end{array}$ & $\begin{array}{l}0.020 \\
0.000 \\
0.016 \\
0.001 \\
0.013 \\
0.001\end{array}$ & $\begin{array}{l}0.009 \\
0.000 \\
0.009 \\
0.000 \\
0.009 \\
0.000\end{array}$ & $\begin{array}{l}0.203 \\
0.010 \\
0.148 \\
0.010 \\
0.038 \\
0.010\end{array}$ & $\begin{array}{l}0.227 \\
0.007 \\
0.048 \\
0.007 \\
0.057 \\
0.006\end{array}$ & $\begin{array}{l}0.218 \\
0.012 \\
0.143 \\
0.013 \\
0.043 \\
0.012\end{array}$ \\
\hline $\begin{array}{l}\text { VAWT } \\
\text { Vb } \\
2 \text { Blade }\end{array}$ & $\begin{array}{l}\text { Lo Freq } \\
1 \mathrm{P} \\
2 \mathrm{P} \\
3 \mathrm{P} \\
4 \mathrm{P} \\
5 \mathrm{P}\end{array}$ & $\begin{array}{l}0.017 \\
0.001 \\
0.074 \\
0.001 \\
0.014 \\
0.001\end{array}$ & $\begin{array}{l}0.005 \\
0.000 \\
0.020 \\
0.000 \\
0.009 \\
0.000\end{array}$ & $\begin{array}{l}0.003 \\
0.000 \\
0.013 \\
0.000 \\
0.004 \\
0.000\end{array}$ & $\begin{array}{l}0.065 \\
0.007 \\
0.206 \\
0.009 \\
0.039 \\
0.011\end{array}$ & $\begin{array}{l}0.052 \\
0.004 \\
0.193 \\
0.007 \\
0.038 \\
0.008\end{array}$ & $\begin{array}{l}0.055 \\
0.008 \\
0.188 \\
0.013 \\
0.041 \\
0.014\end{array}$ \\
\hline
\end{tabular}

interest is the total variance due to the $1 P$ - 5P spikes in the VAWT simulation, as listed in Table 3-1. In Figure 3-14, this sum is plotted as a function of mean wind speed for the wind speed spectra, one-blade simulation only. Cases C1 and C2 are marked as squares. The solid line is a leastsquares linear fit to the six values in cases $C 1$ and $C 2$. This 1 ine has the equation:

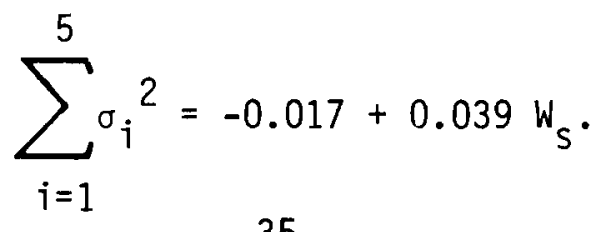




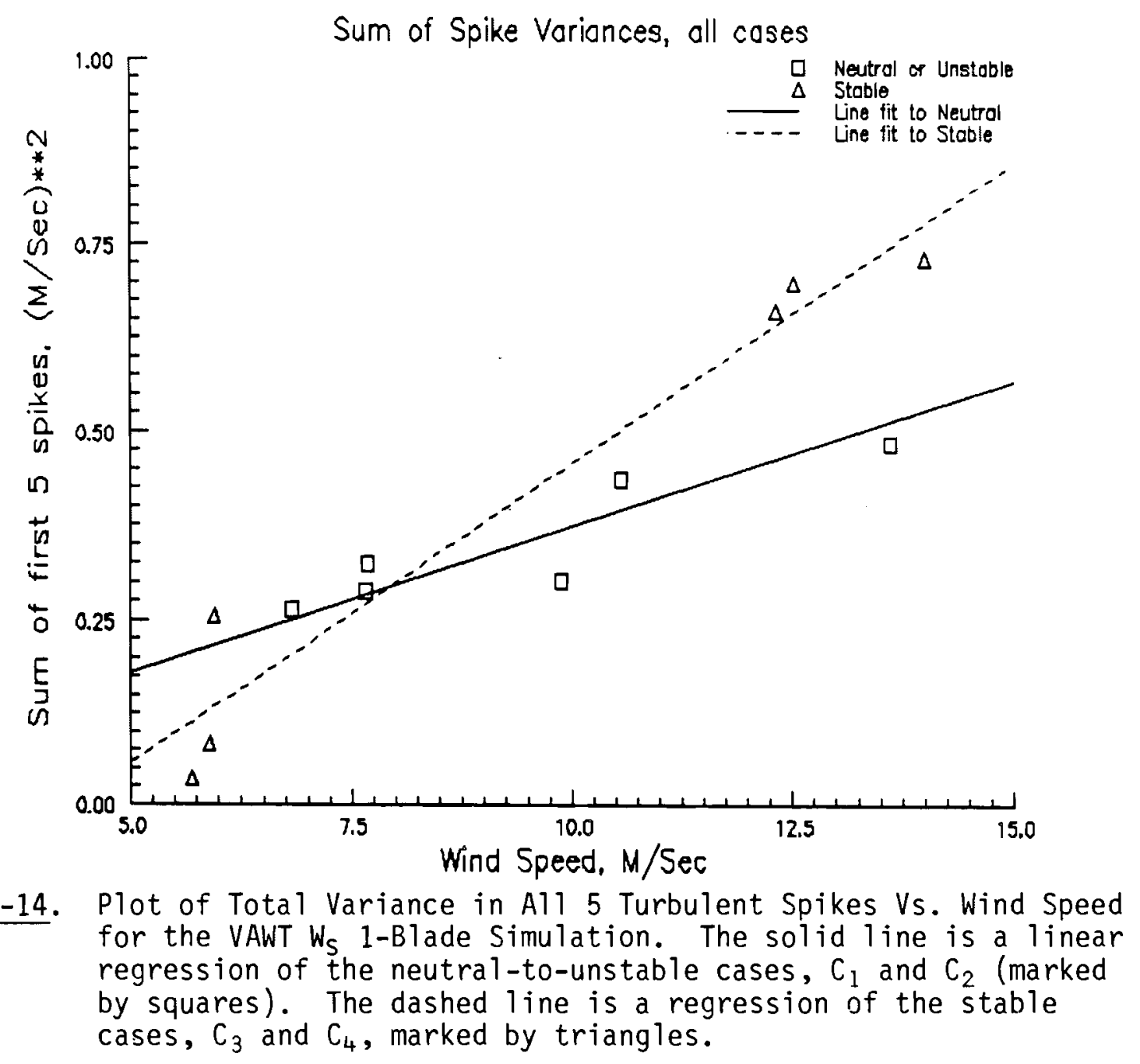

Since this line passes close to $(0,0)$, and since the neutral cases all have similar turbulence properties, this line may be a useful means of predicting the spike variance, given a known mean wind speed over a flat site. A dashed line is drawn as a linear fit to cases $\mathrm{C} 3$ and $\mathrm{C} 4$, shown as triangles on the plot. This line has the equation:

$$
\sum_{i=1}^{5} \sigma_{i}^{2}=-0.343+0.080 w_{s}
$$


However, due to the great differences in turbulence between cases $\mathrm{C} 3$ and $\mathrm{C} 4$, we do not expect this linear relationship to be a useful predictor.

Another parameter which may be of interest is the rate at which the spike variance decreases with increasing frequency. In Figure 3-15, the variance due to each spike is plotted versus frequency on a log-log plot. Most of the traces on this plot seem to be linear. The equation of a straight line on a $\log -\log$ plot has the form:

$$
\sigma_{i}^{2}=K_{0}\left(i n_{0}\right)^{K 1}
$$

where $K o$ is the value for $\sigma_{i}^{2}$ at $n=1.0 \mathrm{~Hz}$ and $K 1$ is the slope of the line. In Table 3-4, the values of Ko and $\mathrm{K} 1$ for a linear curve fit to each case are shown. Once again, these apply only to the VAWT wind speed simulation, one blade. The lines are remarkably similar except for cases C3b and C3c. The average slope of all the other cases is -1.58 . This is very close to the natural slope of a turbulence spectrum on a $\log \log$ plot, which is -1.6667 .

TABLE 3-4. Linear Curve Fit Coefficients to Spike Profiles for 12 Data Cases Used in VAWT Simulations

\begin{tabular}{|c|c|c|c|c|}
\hline Case \# & $\begin{array}{l}\text { Mean Ws } \\
\mathrm{M} / \mathrm{Sec}\end{array}$ & $\begin{array}{c}\text { VAWT } \\
\text { Spike } \sigma^{2} \\
M^{2} / S^{2} \\
\end{array}$ & $\begin{array}{c}\mathrm{Ko} \\
\mathrm{M}^{2} / \mathrm{S}^{2} \\
\end{array}$ & $\mathrm{~K} 1$ \\
\hline $\mathrm{Cla}$ & 7.66 & 0.286 & 0.088 & -1.46 \\
\hline $\mathrm{Clb}$ & 6.82 & 0.263 & 0.082 & -1.55 \\
\hline $\mathrm{Clc}$ & 7.68 & 0.322 & 0.100 & -1.57 \\
\hline $\mathrm{C} 2 \mathrm{a}$ & 9.87 & 0.301 & 0.093 & -1.51 \\
\hline $\mathrm{c} 2 \mathrm{~b}$ & 10.56 & 0.435 & 0.133 & -1.73 \\
\hline $\mathrm{C} 2 \mathrm{c}$ & 13.61 & 0.483 & 0.150 & -1.58 \\
\hline c3a & 5.95 & 0.255 & 0.080 & -1.70 \\
\hline C3b & 5.90 & 0.082 & 0.025 & -1.13 \\
\hline C3c & 5.70 & 0.034 & 0.010 & -0.97 \\
\hline $\mathrm{C} 4 \mathrm{a}$ & 12.52 & 0.700 & 0.220 & -1.49 \\
\hline C4b & 12.32 & 0.662 & 0.206 & -1.71 \\
\hline C4c & 14.00 & 0.732 & 0.222 & -1.45 \\
\hline
\end{tabular}




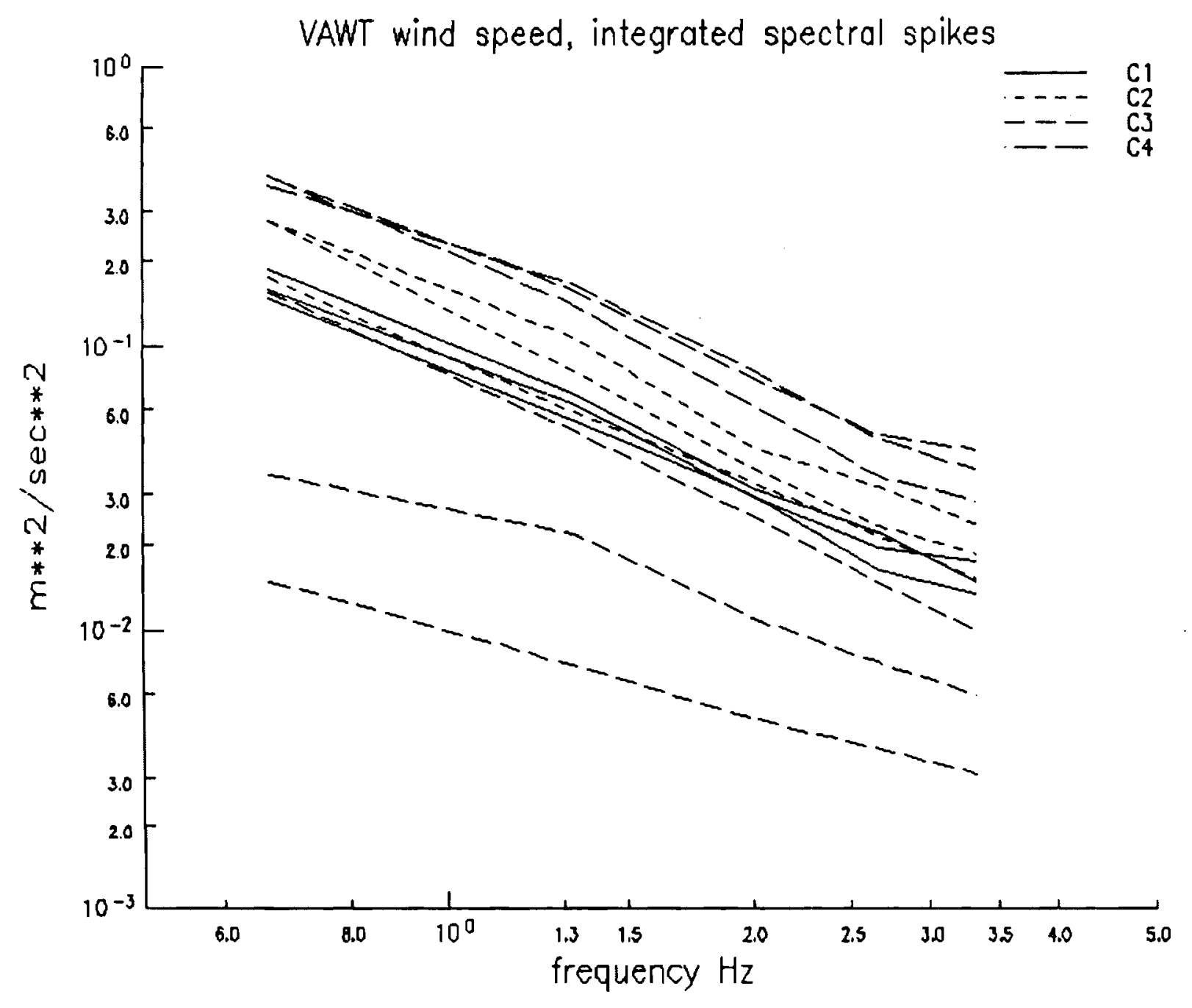

FIGURE 3-15. Plot of Variance, $\sigma_{i}^{2}$, in Each Individual Spike, Vs. Frequency, for All 12 Data Cases. The four types of cases are shown as different line types, as shown on the figure labels. 


\subsection{CONCLUSIONS AND COMPARISONS}

In this study, the free-stream turbulent wind, as seen by a rotating Vertical Axis Wind Turbine (VAWT) blade, has been simulated using an array of fixed anemometers. Spectral plots of the resultant winds have been produced for a wide range of wind conditions.

\subsection{GENERAL CONCLUSIONS}

These results lead to some general conclusions, as follows:

- Generally, the characteristic rotationally sampled spectrum, with spikes at all harmonics of the blade rotation rate for one-blade simulations and at even harmonics only for two-blade simulations, occurs for all simulations. In all cases, parts of the high frequency spectrum exceed the theoretical fixed point Eulerian spectrum. At low tip speed ratios (high wind speeds or slower blade rotation rates), the $4 \mathrm{P}$ and $5 \mathrm{P}$ spikes are of the same magnitude as the general increase in spectral density, and thus do not stand out on the spectral plots. Lowpass filtering of the wind data before rotational sampling can be used to reveal the discrete nature of the $4 \mathrm{P}$ and $5 \mathrm{P}$ spikes.

- The variance contained in the high frequency spikes for a VAWT wind speed spectrum is only a little less than the variance for a Horizontal Axis Wind Turbine (HAWT) simulation, which contains mean wind shear effects, for low-wind speed neutral cases. VAWT variance is much less than HAWT variance for highly sheared winds.

- Neutral-to-unstable winds show a roughly linear increase in wind speed variance with increasing wind speed. The increase has a slope of about $0.039 \mathrm{~m}^{2} / \mathrm{sec}^{2}$ of variance per $\mathrm{m} / \mathrm{sec}$ of wind speed, for a $38.1 \mathrm{~m}$ diameter VAWT with the equator elevated $30.5 \mathrm{~m}$ above the ground. We would expect the slope to be less for a smaller diameter, but greater for a wind turbine closer to the ground.

- At higher wind speeds (above $10 \mathrm{~m} / \mathrm{sec}$ ), more stable nighttime cases have more variance in the high frequency spikes than neutral cases with the 
same wind speed. This is probably due to a slight shift in spectral energy toward higher frequencies in the more stable cases. At low wind speeds, stable cases have much less spike variance than neutral or unstable cases.

- The size of individual spectral spikes relative to each other decrease with increasing frequency in a characteristic way, for $W_{s}$ spectra only. This decrease has a slope close to $-5 / 3$, which is the natural decrease in turbulence energy with increasing frequency.

- Generally, both $U_{b}$, the tangential wind observed at the blade, and $V_{b}$, the radial wind observed at the blade, are dominated by the $1 P$ harmonic spike, due to rotation of the blade through the mean wind. The $2 P$ through $5 P$ spikes in the $U_{b}$ and $V_{b}$ spectra are similar in size to those on the $W_{S}$ spectra.

\subsection{COMPARISON OF RESULTS WITH DIRECT MEASUREMENTS}

Our results can be compared with a direct measurement of the wind using pitot-static wind sensors mounted on the blade leading edge of a 17-m Darrieus VAWT (Akins 1983). Normalized spectral plots of the dynamic pressure for two different wind cases are shown in Figure 4-1. Figure 4-1a is for a wind speed of 13.3, tip speed ratios of 2-3, and wind turbine power close to rated.

Figure 4-1b is for a light wind speed case, tip speed ratios of 5-6, and power about $20 \%$ of rated. Surprisingly, the lower wind speed spectrum (Figure 4-1b) resembles the rotationally sampled wind speed $W_{S}$ from $c l a y t o n$ more so than the tangential wind speed $U_{b}$, with $2 P$ and higher spikes only slightly smaller than the 1P spike. Figure 4-1a, the higher wind speed case, is more dominated by the IP spike, like the $U_{b}$ simulation.

In order to usefully compare these two methods of measuring the vertical axis wind, it is necessary to assess the effects of factors other than atmospheric turbulence on the results. We expect almost no outside effects on the VAWT simulation from Clayton. The Darrieus VAWT measurements, however, are strongly affected by rotation of the blade through the rotor wake on both the downwind and upwind sides of the wind turbine. The steady-state wake, as 

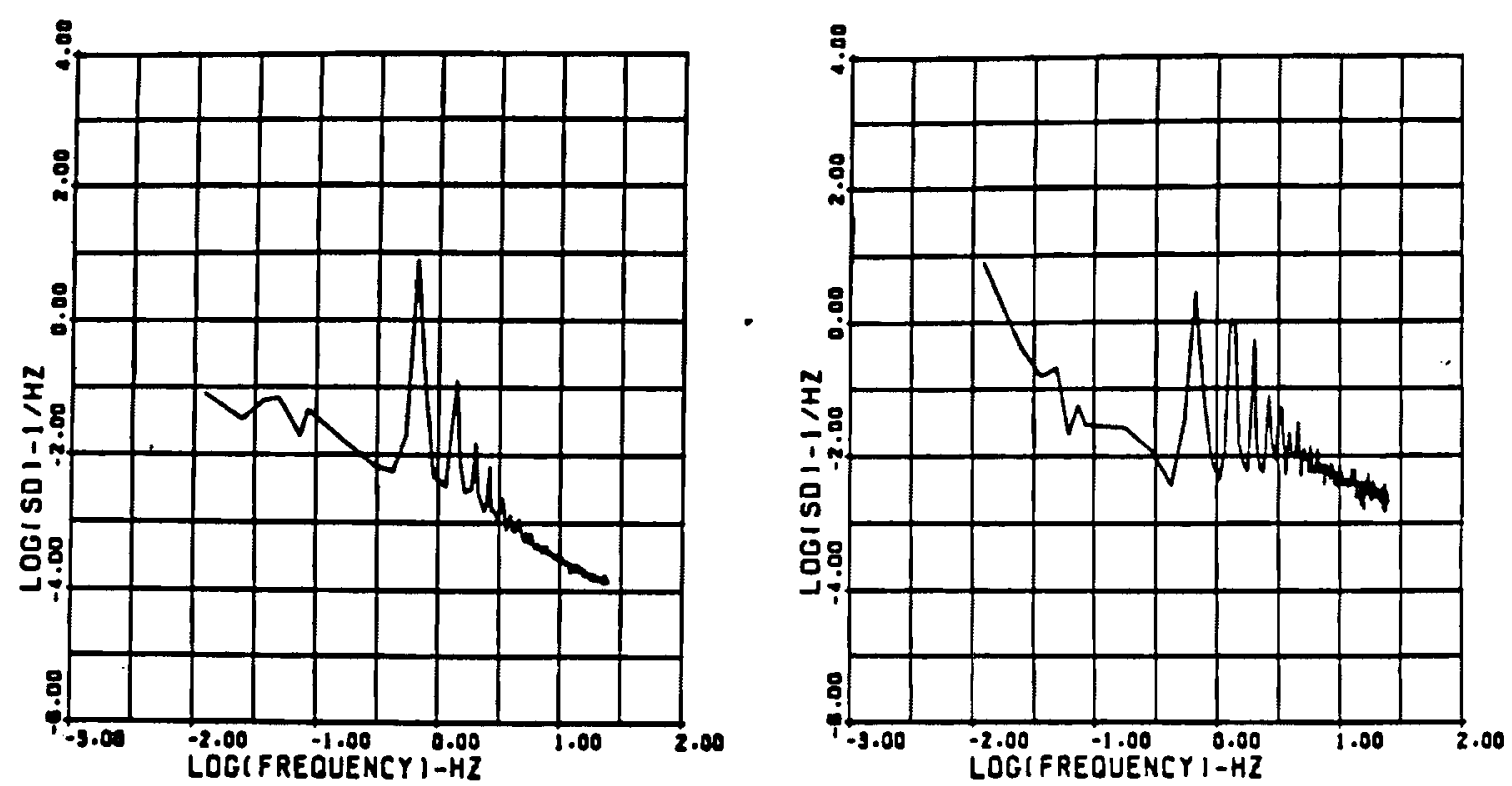

FIGURE 4-1. Spectral Density Plots of Pitot-Static Pressure. Measured from the blade of an operating $17 \mathrm{~m}$ Darrieus VAWT. Figures are a) VAWT power near rated, tip speed ratio 2-3, and b) VAWT power $20 \%$ or rated, tip speed ratio of 5-6 (Akins 1983).

estimated using double multiple streamtube (DMS) models (e.g., Paraschivoiu 1981) would produce a complex velocity reduction as a function of the blade position relative to the wake. This in turn would produce spectral energy at harmonics greater than 1P, helping to explain the differences between the Clayton and VAWT measurements.

An additional component of the wind observed at the VAWT blade, however, can be estimated only by including turbulence effects in the wind. The importance of this component to the VAWT design process has yet to be determined. The resemblance of the observed spectra in Figure 4-1 to the rotationally sampled winds from clayton would suggest an important role for turbulent wind inputs. Recent improvements to DMS models have included the use of turbulent wind inputs.

An interesting extension of this work would be to use clayton Vertical Plane Array data as an input to an advanced DMS model. The dimensions of the VPA correspond almost exactly to the $38 \mathrm{~m}$ "testbed" wind turbine being proposed for the Sandia National Labs facility. Data from the entire array, rather than just from one level, would be used in this application. 
. 


\subsection{REFERENCES}

Akins, R. E. 1983. "Rotationally-Sampled Flow Field Measurements for VerticalAxis Wind Turbines." Presented at the University of Missouri-Columbia Wind/Solar Energy Technology Conference, Kansas City, Missouri. Wind Energy Research Division, Sandia National Laboratories, Albuquerque, NW 87185 .

Chan, S. M., D. C. Powell, M. Yoshimura and D. H. Curtice. 1983. "Operations Requirements of Utilities With Wind Power Generation." IEEE Transactions on Power Apparatus and Systems, PAS-102(9):2850-2860.

Connell, J. R. 1981. The Spectrum of Wind Speed Fluctuations Seen by a Rotating Blade of a Wind Energy Conversion System: Observations and Theory. PNL-4083, Pacific Northwest Laboratory, Richland, WA 99352.

Conne11, J. R. and R. L. George. 1982. The Wake of the MOD-OA1 Wind Turbine at Two Rotor Diameters Downwind on December 3, 1981. PNL-4210, Pacific Northwest Laboratory, Richland, WA 99352.

Conne11, J. R. and R. L. George. 1983a. "A New Look at Turbulence Experienced by a Rotating Wind Turbine." Presented at Energy Sources Technology Conference and Exhibition, January 30-February 3, 1983, Houston, Texas. American Society of Mechanical Engineers, 345 East 47th Street, New York, NY 10017.

Connel1, J. R. and R. L. George. 1983b. PNL-SA-10860. "Scaling Wind Characteristics for Designing Small and Large Wind Turbines." Presented at the ASES Annual Meeting (Wind Workshop VI), Minneapolis/Saint Paul, June 1-3, 1983.

Doran, J. C. and K. R. Packard. 1982. Comparison of Model and Observations of the Wake of a MOD-OA Wind Turbine. PNL-4433, Pacific Northwest Laboratory, Richland, WA 99352.

Horst, T. W. 1973. "Corrections for Response Errors in a Three-Component Propeller Anemometer." J. of App1. Meteor., 12(6):716-725.

Miller, A. H. and W. J. Formica. 1983. Development and Verification of MOD-2 and MOD-OA Simulation Models. PNL -4864 , Pacific Northwest Laboratory, Richland, WA 99352.

Paraschivoiu, I. 1981. Double-Multiple Streamtube Model for Darrieus Wind Turbines. 2nd DOE/NASA Wind Turbine Dynamics Workshop, Cleveland, Ohio.

Verholek, G. 1978. Preliminary Results of a Field Experiment to Characterize Wind Flow Through a Vertical Plane. PNL-2518, Pacific Northwest Laboratory, Richland, WA 99352. 
. 


\section{DISTRIBUTION}

No. of

Copies

OFFSITE

J. Cadogan

Department of Energy

Wind Energy Technology Division

1000 Independence Avenue

Forrestal Building, Room 5H048

Washington, DC 20585

L. V. Divone

Department of Energy

Wind Energy Technology Division

1000 Independence Avenue

Forrestal Building, Room $5 \mathrm{H} 048$

Washington, DC 20585

G. P. Tennyson

Department of Energy

Albuquerque Operations Office

4501 Indian School Road N.E.

Albuquerque, NM 87110

27 DOE Technical Information Center

Peter Lissaman

Aerovironment, Inc.

145 Vista Avenue

Pasadena, CA 91107

D. K. Ai

Alcoa Laboratories

Alcoa Technical Center

Alcoa Center, PA 15069

Tom Gray

American Wind Energy Association

2010 Massachusetts Avenue

Fourth Floor

Washington, DC 20036

W. A. Vachon

Arthur D. Little, Inc.

20 Acorn Park

Cambridge, MA 02140
No. of

Copies
Don McGrew

Boeing Engineering and Construction

P.0. Box 3707, Mail Stop 9A-67

Seattle, WA 98124

Professor Arnold Court Department of Geography

California State University

Northridge, CA 91130

R. N. Meroney

Department of Civil Engineering

Colorado State University

Fort Collins, CO 80523

James Telford

Desert Research Institute

Atmospheric Sciences Center

University of Nevada System

P.0. Box 60220

Reno, NV 89506

2 Dr. Edgar DeMeo/Frank Goodman, Jr. Electric Power Research Institute $3412 \mathrm{Hillview} \mathrm{Avenue}$

Palo Alto, CA 94303

George Ficht 1

7703 Oakridge Drive

Huntsville, AL 35802

2 Tom Hiester/J. J. Riley

Flow Wind Corporation

21414-68th Avenue South

Kent, WA 98031

Walter Frost

FWG Associates, Inc. 271A Lakewood Drive

Tullahoma, TN 37388 
No. of

Copies

Robert Barton

Advanced Energy Power Division

General Electric Company

Mai1 Stop 7310

501 Allendale Road, P.0. Box 527

King of Prussia, PA 19406

Art Jackson

Hamilton Standard Division

United Technologies Corporation

Windsor Lock, CT 06096

2 J. M. Kos/Eugene Di Valentin

Hamilton Standard

Bradley Field Road

Windsor Locks, CT 06096

M. A. Bowes

Kaman Aerospace Corporation

0ld Windsor Road

Bloomfield, CT 06095

David Spera

NASA/Lewis Research Center

21000 Brookpark Road

Cleveland, $\mathrm{OH} 44135$

Joe Savino

Wind Turbine Group

NASA/Lewis Research Center

21000 Brookpark Road

Cleveland, $\mathrm{OH} \quad 44135$

3 Phillip French

NASA Scientific and Technical Information Facility

P.0. Box 8757

Baltimore/Washington International Airport

Baltimore, MD 21240

2 J. C. Kaimal/W. Hooke

National Oceanic and Atmospheric Administration/Environmental Research Laboratories/Wave Propagation Laboratory

3000 Marine Street

Boulder, CO 80302
No. of

Copies

Jerry Gregorck

Ohio State University

Columbus, $\mathrm{OH} 43210$

Peter M. Moretti

Oklahoma State University

Mechanical and Aerospace

Engineering

Engineering North 218

Stillwater, OK 74074

3 W. Holley/R. Thresher/B. Wilson

Oregon State University

Corvallis, OR 97331

R. Lee Cresap

Pacific Gas \& Electric Company

Room 1385

77 Beale Street

San Francisco, CA 94106

R. L. Simon

Pacific Gas and Electric

215 Market Street

San Francisco, CA 94106

2 J. Dutton/H. A. Panofsky

Department of Meteorology

Pennsylvania State University

University Park, PA 16902

3 Ernel L. Luther

Planning Research Corporation

1500 Planning Research Drive

McLean, VA 22102

J. P. Sullivan

331 Grissom Hal1

Purdue University

West Lafayette, IN 47907

Jim Tangler

Rockwell International

Rocky Flats Plant

P.0. Box 464

Golden, C0 80401 
No. of

Copies

3 E. Kadlec

Sandia Laboratories

Division 5443, P.0. Box 5800

Albuquerque, NM 87115

Paul Veers

Sandia Laboratories

Division 1524, P.0. Box 5800

Albuquerque, NM 87115

Neil Kelley

Solar Energy Research Institute

1617 Cole Boulevard

Golden, CO 80401

Sherman M. Chan

Systems Control, Inc.

1801 Page Mill Road

P.0. Box 10025

Palo Alto, CA 94303

J. H. Strickland

Mechanical Engineering Department

Texas Tech University

Lubbock, TX 79409

R. H. Kirchhoff

Department of Mechanical Engineering

University of Massachusetts

Amherst, MA 01003

Earl L. Davis

U.S. Windpower, Inc.

2305 S. Vasco Road

Livermore, CA 94550

Paul Vosburgh

VAWT Power, Inc.

Albuquerque, New Mexico

H. Tielman

Department of Engineering Science \& Mechanics

Virginia Polytechnic Institute and State University

Blacksburgs, VA 24061
No. of

Copies

R. E. Akins

Associate Professor of Engineering Washington and Lee University

Lexington, VA 24450

Farrell Smith Seiler

Wind Energy Report

Box 14 - 104 S. Village Avenue

Rockville Centre, NY 11571

Dr. V. Barros

28 De Julio 28

9120 Puerto Madryn

Chulret R. ARGENTINA

Lawrence Schienbein

DAF Indal

Mississauga, Ontario

CANADA

Bernard Masse

1800 Montee Ste-Julie

Varennes

Quebec, CANADA JOL 2PO

R. J. Templin

National Research Council of

Canada

National Aeronautical

Establishment

M-2 Montreal Road

Ottawa, Ontario

CANADA K1A OR6

Leif Kristensen

Department of Physics

Ris $\varnothing$ National Laboratory

4000 Roskilde

DENMARK

Per Lundsager

Ris $\varnothing$ Nationa 1 Laboratory

P.0. Box 49

DK-4000 Roskilde

DENMARK 
No. of

Copies

Professor Sir Martin Ryle

Cavendish Laboratory

Madingley Road

Cambridge CB3 OHE

ENGLAND

H. H. Rosenbrock

The University of Manchester

Institute of Science and Technology

P.0. Box No. 88

Manchester M60 1QD

ENGLAND

D. Lindley

Taylor Woodrow Construction, Ltd.

Taywood House

345 Ruislip Road

Southa 11

Middlesex UBI 2QX

ENGLAND

Andre Laneville

University of Sherbrooke

Quebec, CANADA

Dr. Werner Dub

Forschungsprojekt Windenergie

Universitatsstrasse 31

D-8400 Regensburg

GERMANY, FRG

Dr. Neil Cherry

Lincoln College

Canterbury

NEW ZEALAND
No. of

Copies

Dr. 011e Ljungstrom

FFA, The Aeronautical Research Institute

Forskningsstationen i Stockholm

Drottning Kristinas Vag 47

S-114 29 Stockholm

SWEDEN

\section{ONSITE}

DOE Richland Operations Office

H. E. Ransom

32 Pacific Northwest Laboratory

J. R. Connel1

J. C. Doran

D. W. Dragnich

C. E. Elderkin

R. L. George (5)

D. L. Hadley

P. C. Hays

S. K. Heflick

T. W. Horst

A. H. Miller

D. C. Powe 11

D. S. Renne

H. L. Wegley

L. L. Wende 11

C. D. Whiteman

R. K. Woodruff

Technical Information Files (5)

Publishing Coordination (2)

WCPE Program Office (5) 